\title{
Re-parameterization of a quasi-analytical algorithm for colored dissolved organic matter dominant inland waters
}

\author{
Igor Ogashawara $^{\mathrm{a}, *}$, Deepak R. Mishra ${ }^{\mathrm{b}}$, Renata F.F. Nascimento ${ }^{\mathrm{c}}$, Enner H. Alcântara ${ }^{\mathrm{d}}$, \\ Milton Kampel ${ }^{\mathrm{e}}$, Jose L. Stech ${ }^{\mathrm{e}}$
}

a Indiana University-Purdue University Indianapolis, Department of Earth Sciences, Indianapolis, IN, USA

b Center for Geospatial Research, University of Georgia, Department of Geography, Athens, GA, USA

' Geopixel, São José dos Campos, SP, Brazil

d São Paulo State University, Department of Cartography, Presidente Prudente, SP, Brazil

e National Institute for Space Research, Remote Sensing Division, São José dos Campos, SP, Brazil

\section{A R T I C L E I N F O}

\section{Article history:}

Received 15 February 2016

Received in revised form 15 August 2016

Accepted 1 September 2016

\section{Keywords:}

Bio-optical model

Colored dissolved organic matter

Inland waters

Quasi-analytical algorithm

Inherent optical properties

Absorption coefficient of phytoplankton

Remote sensing reflectance

\begin{abstract}
A B S T R A C T
Quasi-Analytical Algorithms (QAAs) are based on radiative transfer equations and have been used to derive inherent optical properties (IOPs) from the above surface remote sensing reflectance $\left(R_{r s}\right)$ in aquatic systems in which phytoplankton is the dominant optically active constituents (OACs). However, Colored Dissolved Organic Matter (CDOM) and Non Algal Particles (NAP) can also be dominant OACs in water bodies and till now a QAA has not been parametrized for these aquatic systems. In this study, we compared the performance of three widely used QAAs in two CDOM dominated aquatic systems which were unsuccessful in retrieving the spectral shape of IOPS and produced minimum errors of $350 \%$ for the total absorption coefficient $(a)$, 39\% for colored dissolved matter absorption coefficient $\left(a_{C D M}\right)$ and $7566.33 \%$ for phytoplankton absorption coefficient $\left(a_{p h y}\right)$. We re-parameterized a QAA for CDOM dominated (hereafter $\mathrm{QAA}_{\mathrm{CDOM}}$ ) waters which was able to not only achieve the spectral shape of the OACs absorption coefficients but also brought the error magnitude to a reasonable level. The average errors found for the 400-750 nm range were 30.71 and 14.51 for $a, 14.89$ and 8.95 for $a_{C D M}$ and 25.90 and 29.76 for $a_{p h y}$ in Funil and Itumbiara Reservoirs, Brazil respectively. Although $\mathrm{QAA}_{\mathrm{CDOM}}$ showed significant promise for retrieving IOPs in CDOM dominated waters, results indicated further tuning is needed in the estimation of $a(\lambda)$ and $a_{\text {phy }}(\lambda)$. Successful retrieval of the absorption coefficients by QAA $A_{C D O M}$ would be very useful in monitoring the spatio-temporal variability of IOPS in CDOM dominated waters.
\end{abstract}

(c) 2016 Elsevier B.V. All rights reserved.

\section{Introduction}

Chlorophyll- $a$ (chl- $a$, refer to Table 1 for symbols and acronyms) concentration is essential for monitoring water quality in aquatic systems since it is an estimator of their trophic state. It is also an indicator of primary production and algal blooms, especially toxic cyanobacterial blooms in reservoirs, lakes, and estuaries (Reinart and Kutser, 2006). Chl- $a$ is often considered as a proxy for algal biomass and has been used as an indicator of ecological health of

\footnotetext{
* Corresponding author at: (I.O.) Indiana University-Purdue University Indianapolis, Department of Earth Sciences, 723 West Michigan Street, SL118, 46202, Indianapolis, IN, USA.

E-mail addresses: igorogas@iupui.edu, igoroga@gmail.com (I. Ogashawara), dmishra@uga.edu (D.R. Mishra),re_ffnascimento@yahoo.com.br (R.F.F. Nascimento), enner@fct.unesp.br (E.H. Alcântara), milton@dsr.inpe.br (M. Kampel), stech@dsr.inpe.br (J.L. Stech).
}

waters. Traditional monitoring methods of chl- $a$ are based on field sampling and laboratory analysis which are expensive and time consuming (Duan et al., 2010). Moreover, their spatial and temporal heterogeneity make point field sampling inadequate for monitoring large areas (Gons, 1999). Remote sensing techniques have been extensively used for monitoring chl- $a$ in aquatic inland systems (Dall'Olmo and Gitelson, 2005; Gitelson et al., 2007, 2008, 2009; Le et al., 2009a, 2011; Mishra and Mishra, 2012). Advantages in remote monitoring are: (1) synoptic view of satellite images allow the acquisition of data from the entire aquatic system; (2) the capability of obtaining information from remote and sometimes inaccessible regions; and (3) the availability of historical series of data allowing the extraction of information from the past (Hadjimitsis and Clayton, 2009). Accordingly, Gons (1999) observed that the use of remote sensing techniques were time saving, cost-effective, and scientifically rewarding alternative. 
Table 1

List of symbols and acronyms on bio-optical modeling.

\begin{tabular}{|c|c|c|}
\hline Symbol/acronym & Description & Unit \\
\hline IOPs & Inherent optical properties & - \\
\hline AOPs & Apparent optical properties & - \\
\hline QAA & Quasi-analytical algorithm & - \\
\hline CDOM & Colored dissolved organic matter & - \\
\hline NAP & Non algal particles & - \\
\hline CDM & Colored detritus matter (CDOM + NAP) & - \\
\hline chl- $a$ & Chlorophyll- $a$ & - \\
\hline PC & Phycocyanin & - \\
\hline$Q$ & Light distribution factor & $\mathrm{sr}$ \\
\hline$f$ & Geometrical light factor & \\
\hline$R_{r s}$ & $\begin{array}{l}\text { Remote sensing reflectance above water } \\
\text { surface }\end{array}$ & $\mathrm{sr}^{-1}$ \\
\hline$r_{r s}$ & $\begin{array}{l}\text { Remote sensing reflectance below water } \\
\text { surface }\end{array}$ & $\mathrm{sr}^{-1}$ \\
\hline$L_{u}\left(0^{-}, \lambda\right)$ & $\begin{array}{l}\text { Spectral Upwelling radiance below water } \\
\text { surface }\end{array}$ & $\mathrm{Wm}^{-2} \mathrm{sr}^{-1}$ \\
\hline$L_{s k y}\left(0^{-}, \lambda\right)$ & Sky radiance & $\mathrm{W} \mathrm{m} \mathrm{m}^{-2} \mathrm{sr}^{-1}$ \\
\hline$L_{r e f}\left(0^{-}, \lambda\right)$ & Spectralon reference panel radiance & $\mathrm{W} \mathrm{m}^{-2} \mathrm{sr}^{-1}$ \\
\hline$L_{w}\left(0^{-}, \lambda\right)$ & Water leaving radiance & $\mathrm{W} \mathrm{m} \mathrm{m}^{-2} \mathrm{sr}^{-1}$ \\
\hline$E_{d}\left(0^{-}, \lambda\right)$ & $\begin{array}{l}\text { Spectral downwelling irradiance bellow water } \\
\text { surface }\end{array}$ & $\mathrm{W} \mathrm{m}^{-2} \mathrm{sr}^{-1}$ \\
\hline$E_{s}\left(0^{+}, \lambda\right)$ & $\begin{array}{l}\text { Spectral incident irradiance above water } \\
\text { surface }\end{array}$ & $\mathrm{W} \mathrm{m}^{-2} \mathrm{sr}^{-1}$ \\
\hline$a(\lambda)$ & Spectral total absorption coefficient & $\mathrm{m}^{-1}$ \\
\hline$a_{p}(\lambda)$ & $\begin{array}{l}\text { Spectral absorption coefficient of particulate } \\
\text { matter }\end{array}$ & $\mathrm{m}^{-1}$ \\
\hline$a_{p h y}(\lambda)$ & $\begin{array}{l}\text { Spectral absorption coefficient of } \\
\text { phytoplankton }\end{array}$ & $\mathrm{m}^{-1}$ \\
\hline$a_{N A P}(\lambda)$ & $\begin{array}{l}\text { Spectral absorption coefficient of non-algal } \\
\text { particles }\end{array}$ & $\mathrm{m}^{-1}$ \\
\hline$a_{C D M}(\lambda)$ & $\begin{array}{l}\text { Spectral absorption coefficient of colored } \\
\text { detritus matter }\end{array}$ & $\mathrm{m}^{-1}$ \\
\hline$a_{\text {СDOM }}(\lambda)$ & $\begin{array}{l}\text { Spectral absorption coefficient of colored } \\
\text { dissolved organic matter }\end{array}$ & $\mathrm{m}^{-1}$ \\
\hline$a_{w}(\lambda)$ & Spectral absorption coefficient of pure water & $\mathrm{m}^{-1}$ \\
\hline$b_{b}(\lambda)$ & Spectral total backscattering coefficient & $\mathrm{m}^{-1}$ \\
\hline$b_{b, w}(\lambda)$ & $\begin{array}{l}\text { Spectral backscattering coefficient of pure } \\
\text { water }\end{array}$ & $\mathrm{m}^{-1}$ \\
\hline$b_{b, p}(\lambda)$ & $\begin{array}{l}\text { Spectral backscattering coefficient of } \\
\text { particulate matter }\end{array}$ & $\mathrm{m}^{-1}$ \\
\hline$b_{b, p h y}(\lambda)$ & $\begin{array}{l}\text { Spectral backscattering coefficient of } \\
\text { phytoplankton }\end{array}$ & $\mathrm{m}^{-1}$ \\
\hline$b_{b, N A P}(\lambda)$ & $\begin{array}{l}\text { Spectral backscattering coefficient of non-algal } \\
\text { particles }\end{array}$ & $\mathrm{m}^{-1}$ \\
\hline [chl- $a$ ] & Chlorophyll- $a$ concentration & $\mu \mathrm{g} / \mathrm{L}$ \\
\hline [NAP] & Non algal particles concentration & $\mathrm{mg} / \mathrm{L}$ \\
\hline
\end{tabular}

Remote sensing of chl- $a$ is based on relating different spectral characteristics of chl- $a$ such as absorption, scattering, and fluorescence in mathematical or physical algorithms. These algorithms, also known as bio-optical models, have been applied on aquatic systems worldwide and can be classified into three categories: semi-empirical, semi-analytical, and quasi-analytical (Odermatt et al., 2012). Semi-empirical algorithms such as red-near infrared (NIR) band ratio (Dall'Olmo and Gitelson, 2005; Moses et al., 2009), fluorescence line height (Gons et al., 2008; Hu et al., 2005), threeband tuning algorithms (Dall'Olmo and Gitelson, 2005; Gitelson et al., 2007, 2008, 2009), four-band algorithms (Le et al., 2009b) and Normalized Difference Chlorophyll Index (NDCI) (Mishra and Mishra, 2012) have been used to monitor chl- $a$ in inland waters. However, they are usually limited to the environmental conditions of the specific aquatic system and empirical calibrations are often required (Matthews et al., 2010). On the other hand, analytical algorithms are based on radiative transfer equations and since it is based on physical principles, they should be useful in different water bodies (Li et al., 2013). Therefore, the International Ocean Colour Coordinating Group (IOCCG) suggested deriving inherent optical properties (IOPs) rather than directly estimating chl- $a$ concentration from the above-surface remote sensing reflectance $\left(R_{r s}\right)$ for highly turbid inland waters (IOCCG, 2006; Li et al., 2011, 2013,
2015; Gons et al., 2002; Mishra et al., 2013, 2014). That way, the estimated absorption coefficient of phytoplankton $\left(a_{p h y}\right)$ can be used to quantify chl- $a$ concentration (Gilerson et al., 2010; Li et al., 2013). These IOP decomposition algorithms first proposed by Lee et al. (2002) are termed as quasi-analytical algorithms (QAA).

QAAs have been proposed to estimate the IOPs from ocean waters (Lee et al., 2002, 2009) and several re-parameterized versions have been used for in inland waters (Li et al., 2013, 2015; Mishra et al., 2014). However, all the previously published versions of QAA in the literature are found to be calibrated and validated in aquatic systems in which $a_{p h y}$ was the dominant IOP. Therefore, the use of those QAAs for monitoring chl- $a$ in aquatic systems in which phytoplankton is not the dominant component is still a challenge (Gons et al., 2008; Li et al., 2013), mainly due to the dominance of other optically active constituents (OACs) such as colored dissolved organic matter (CDOM) and non-algal particles (NAP). These two constituents have absorption features that usually overlap with chl- $a$ mainly in the blue and green spectral channels. These characteristics do not allow the existing QAAs to accurately retrieve IOPs in waters dominated by CDOM and NAP, since most of the bands used in the QAAs are located in the blue and green wavelengths.

The main goal of the present study was to parameterize an existing QAA to retrieve the IOPs in CDOM dominated waters, since to the best of our knowledge, there has not been any semi-analytical model or QAA developed or parameterized specifically for CDOM dominated tropical inland waters. The objectives of this research were: (1) to evaluate the performance of the existing QAA using in situ and bio-optical dataset acquired from two CDOM dominated tropical reservoirs; and (2) to re-parameterize a QAA for estimating IOPs in these waters. We anticipate that the successful re-parameterization and implementation of a QAA for CDOM dominated waters will be widely applicable to many inland and shallow marine and estuarine environments where phytoplankton is not the dominant OAC.

\section{Background}

\subsection{IOP derivation}

Several models have been developed to accurately derive the IOPs from the apparent optical properties (AOPs) such as $R_{r s}$ (Maritorena et al., 2002; Lee et al., 2002, 2009). Semi-analytical and QAAs derivation of IOPs is commonly based on the reflectance model shown in Eq. (1) (Gordon et al., 1975, 1988).

$r_{r s}(\lambda)=\frac{L_{u}\left(0^{-}, \lambda\right)}{E_{d}\left(0^{-}, \lambda\right)}=g_{1}\left(\frac{b_{b}(\lambda)}{a(\lambda)+b_{b}(\lambda)}\right)+g_{2}\left(\frac{b_{b}(\lambda)}{a(\lambda)+b_{b}(\lambda)}\right)^{2}$

where, $r_{r s}(\lambda)$ is the remote sensing reflectance just beneath the water surface, $a(\lambda)$ is the spectral total absorption coefficient, $b_{b}(\lambda)$ is the spectral total backscattering coefficient, $L_{u}\left(0^{-}, \lambda\right)$ and $E_{d}\left(0^{-}\right.$, $\lambda)$ are upwelling radiance and downwelling irradiance, respectively, and $g_{1}$ and $g_{2}$ are geometrical factors.

Based on Eq. (1), several semi-analytical and QAA models have been proposed for deriving the IOPs from ocean waters (Roesler and Perry, 1995; Maritorena et al., 2002; Lee et al., 2002). For inland waters, semi-analytical and QAAs have recently been proposed by Simis et al. (2005, 2007), Li et al. (2012, 2013, 2015), and Mishra et al. (2014). The main difference between semi-analytical and QAA is based on the estimation of $a(\lambda)$ and $b_{b}(\lambda)$ (Lee et al., 2002). In QAA, the estimation of $a(\lambda)$ does not involve absorption coefficients of individual constituents such as $a_{p h y}(\lambda)$, spectral absorption coefficient of non-algal particles $\left(a_{N A P}(\lambda)\right)$, and spectral absorption coefficient of color dissolved matter (CDM) $\left(a_{C D M}(\lambda)\right)$. On the contrary, in semi-analytical algorithms (Roesler and Perry, 1995; Maritorena et al., 2002), $a(\lambda)$ is usually estimated by the sum of 
the absorption coefficients of other constituents including spectral absorption coefficient of pure water $\left(a_{w}(\lambda)\right)$ as show in Eq. (2).

$a(\lambda)=a_{w}(\lambda)+a_{p h y}(\lambda)+a_{N A P}(\lambda)+a_{C D O M}(\lambda)$

where, $a_{C D O M}(\lambda)$ is the specific absorption coefficient of CDOM.

On the other hand, in QAA, $a(\lambda)$ is calculated as given in Lee et al. (2009)'s QAA version 5 (QAAv5).

$a(\lambda)=\frac{(1-u(\lambda))\left(b_{b, w}(\lambda)+b_{b, p}(\lambda)\right)}{u(\lambda)}$

where, $u$ is calculated from Eq. (4); $b_{b, w}(\lambda)$ and $b_{b}, p(\lambda)$ are the spectral backscattering coefficients of pure water and particulate matter, respectively.

$u=\frac{b_{b}}{a+b_{b}}$

Estimation of $b_{b}(\lambda)$ in semi-analytical algorithms is usually expressed as the sum of the backscattering coefficients for all optically active constituents in water except for CDOM, as given in Eq. (5).

$b_{b}(\lambda)=b_{b, w}(\lambda)+[$ chl $-a] b_{b, p h y}^{*}(\lambda)+[N A P] b_{b, N A P}^{*}(\lambda)$

where, $b_{b}{ }^{*}$, phy $(\lambda)$ and $b_{b}{ }^{*}$,NAP $(\lambda)$ are the spectral specific backscattering coefficients for phytoplankton and NAP, respectively and [chl-a] and [NAP] are the concentrations of chl- $a$ and NAP, respectively.

In QAA (QAAv5), $b_{b}(\lambda)$ is also calculated differently as given in Eq. (6) (Lee et al., 2009).

$b_{b}(\lambda)=b_{b, w}(\lambda)+b_{b, p}\left(\lambda_{0}\right)\left(\frac{\lambda_{0}}{\lambda}\right)^{\eta}$

where, $\lambda_{0}$ is the reference wavelength, and $\eta$ is the spectral power for backscattering coefficient of particulates and calculated as:

$\eta=2\left(1-1.2 \exp \left(-0.9 \frac{r_{r s}(443)}{r_{r s}\left(\lambda_{0}\right)}\right)\right)$

\subsection{QAA applications for retrieving $\mathrm{a}_{\text {phy }}(\lambda)$}

QAA (Lee et al., 2002) is a multi-band inversion algorithm that uses $R_{r s}(\lambda)$ spectra to retrieve $a(\lambda)$ and $b_{b p}(\lambda)$. It has been extensively validated for ocean waters using both simulated and field datasets from different geographic regions (Lee et al., 2002; Lee and Carder, 2004; Le et al., 2009a). Due to its high accuracy in retrieving IOPs in coastal and open ocean waters, it has been recently re-parameterized to retrieve $a_{p h y}(\lambda)$ in inland waters (Li et al., 2013, 2015; Mishra et al., 2014). Mishra et al. (2014) re-parameterized the QAA for extremely turbid hypereutrophic temperate waters in the United States, where $a_{p h y}(443)\left(3.44-37.67 \mathrm{~m}^{-1}\right)$ contributes $>54 \%$ of the $a(443)\left(4.99-47.21 \mathrm{~m}^{-1}\right)$. Their model was able to retrieve $a_{\text {phy }}(\lambda)$ with an average percentage error of $27.2 \%$ within the $413-665 \mathrm{~nm}$ range. Similar error values were found by $\mathrm{Li}$ et al. (2015) which calculated the relative root mean square error (rRMSE) for the estimations of $a_{\text {phy }}$ at three different wavelengths $(443,620$ and $665 \mathrm{~nm})$. They showed that their model could estimate $a_{\text {phy }}$ with an rRMSE of $28.79,26.60$ and $30.45 \%$ for the band centers at 443, 620 and $665 \mathrm{~nm}$, respectively. These two previous studies were able to estimate $a_{\text {phy }}$ with rRMSE values between $25 \%$ and $31 \%$ in the visible range, in environments where phytoplankton was the dominant OAC.

\section{Materials and methods}

\subsection{Study sites}

Our study was conducted in two different tropical hydroelectric reservoirs in Brazil. The datasets used in this study, in situ spectral data and pigment concentration, were collected by following established protocols for spectral measurements and laboratory analysis.

\subsubsection{Itumbiara hydroeletric reservoir}

The Itumbiara Hydroelectric Reservoir $\left(18^{\circ} 25^{\prime} \mathrm{S}, 4^{\circ} 06^{\prime} \mathrm{W}\right)$ located in central Brazil, between the Minas Gerais and the Goiás States (Fig. 1), was sampled over two field campaigns conducted during May and September of 2009 (Nascimento, 2010). The reservoir was developed by building an embankment dam on the Paranaíba River near Itumbiara in Goiás, Brazil. The region is typically a tropical grassland savanna and its geomorphology helped the reservoir to develop a dendritic pattern with an area of approximately $814 \mathrm{~km}^{2}$ and a volume of $17.03 \times 109 \mathrm{~m}^{3}$ (Alcântara et al., 2010). The reservoir's is situated $520 \mathrm{~m}$ above sea level (m.a.s.l) and has a major axis of $30 \mathrm{~km}$, and a maximum width of approximately $15 \mathrm{~km}$. Its depth ranges from 0.5 to $78 \mathrm{~m}$, with a mean depth of $32 \mathrm{~m}$ (Curtarelli et al., 2013a). The climate of the region is defined by two seasons: dry and cold (May-October) and wet and warm (December-April). The peak of monthly precipitation during the dry season (austral winter) is around $5 \mathrm{~mm}$ while for the wet season (austral summer) the peak reaches up to $250 \mathrm{~mm}$ (Alcântara et al., 2010). The average air temperature during the wet season ranges from 24 to $26^{\circ} \mathrm{C}$, while during the dry season, average temperature stays below $20^{\circ} \mathrm{C}$ (Curtarelli et al., 2013a).The average relative humidity shows a similar pattern to the air temperature, however, it shows a small shift in the minimum value towards September (47\%) (Curtarelli et al., 2013b).

\subsubsection{Funil hydroeletric reservoir}

Funil Reservoir $\left(22^{\circ} 32^{\prime} \mathrm{S}\right.$ and $\left.44^{\circ} 45^{\prime} \mathrm{W}\right)$ drains water from the hydrographic basin of Paraíba do Sul river, in Southeast Brazil (Fig. 1), and it is located between the cities of Itatiaia and Resende in the state of Rio de Janeiro. This hydrographic basin connects three economically important Brazilian states including Minas Gerais, Rio de Janeiro, and São Paulo. The reservoir has a $16,800 \mathrm{~km}^{2}$ catchment area, surface of $40 \mathrm{~km}^{2}$, mean depth of $22 \mathrm{~m}$, maximum depth of $70 \mathrm{~m}$ and total volume of $8.9 \times 10^{9} \mathrm{~m}^{3}$. The retention time varies from 10 to 50 days according to the season of the year (Rocha et al., 2002). The field trip in this study site was conducted in April 2013.

Funil Reservoir was constructed during the late 1960s with the purpose of being an important hydroelectric power generation source (Ogashawara et al., 2013). However, Branco et al. (2002) pointed out that the Funil reservoir also serves as the primary source of drinking water for domestic supply, irrigation, industrial self-supply systems, and aquaculture. Moreover, the reservoir drains the waste from one of the main Brazilian industrial areas with a large range of industries: 19 chemical, 26 siderurgical and metallurgical, 5 electric and electronic, 1 petrochemical, 3 paper and cellulose, and few others food and textile industries (Primo, 2006). Additionally to these industrial waste, Dittmar et al. (2012) found that the Paraíba do Sul River carries 2700 tons per year of dissolved black carbon (DBC) originated mainly by fire-return cycle of sugarcane plantations. The authors also found high concentrations of organic carbon and DBC in the soil of the Paraíba do Sul watershed which could load the aquatic systems in the watershed with organic matter. 


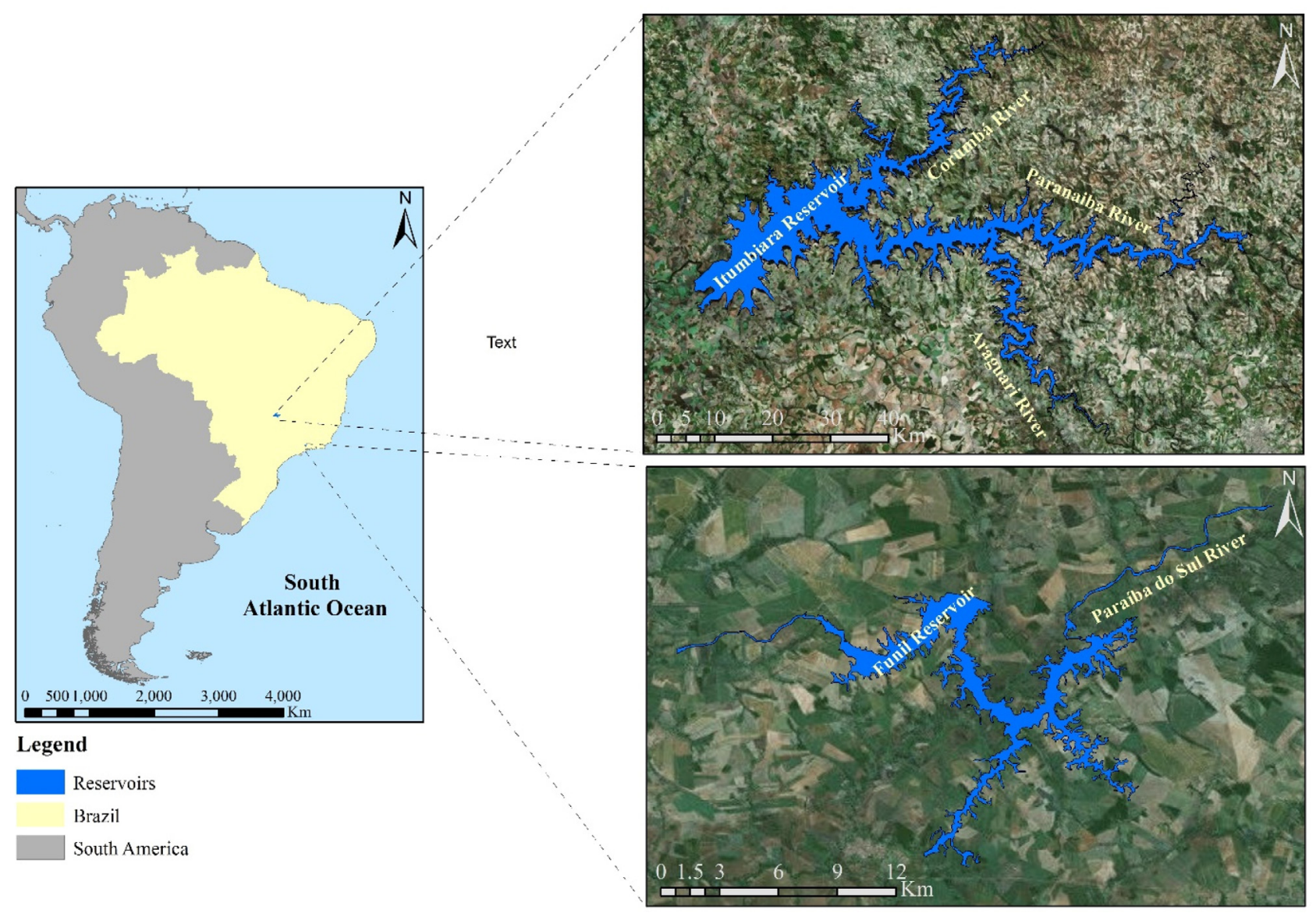

Fig. 1. Location of Itumbiara and Funil Reservoirs, Brazil.
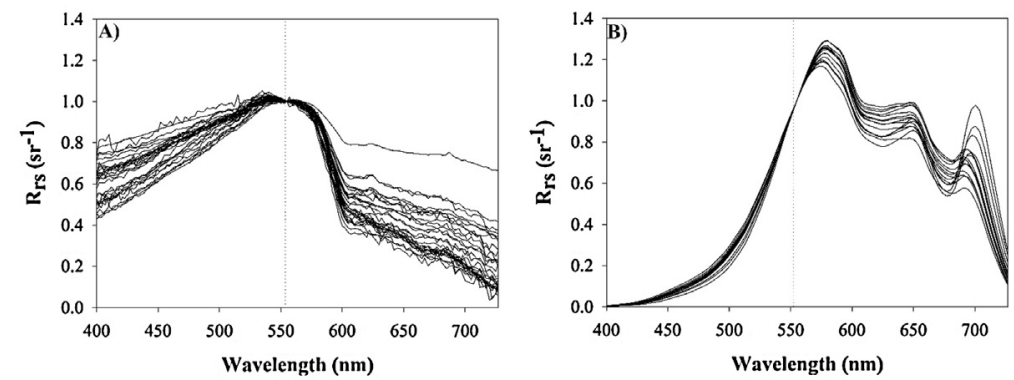

Fig. 2. Normalized $R_{r s}$ spectra by the value at $555 \mathrm{~nm}$ (dotted line) collected in (A) Itumbiara Reservoir; and (B) Funil Reservoir.

\subsection{In situ $R_{r s}$}

The normalized $R_{r s}$ shown in Fig. 2 were measured using two different spectroradiometers, due to this, $R_{r s}$ was calculated differently for each spectroradiometer, since one used submerged and above the surface measurements and the other used only the above the surface measurement. For the Itumbiara Reservoir, we used an ASD field spectrometer (Analytical Spectral Devices, Inc., Boulder, CO, USA) during 12-13 May and 09-11 September of 2009. The measurements were made by following Fougnie et al. (1999)'s method without a polarizer filter. Upwelling radiance $\left(L_{u}\right)$, sky radiance $\left(L_{s k y}\right)$, and spectralon reference panel radiance $\left(L_{r e f}\right)$ were measured nine times at each sampling station to reduce noise variability. $R_{r s}$ was then computed following Mobley (1999) as:

$R_{r s}=\frac{L_{w}\left(0^{+}\right)}{E_{d}\left(0^{+}\right)}=\frac{\left(L_{u}\left(0^{+}\right)-\rho L_{s k y}\left(0^{+}\right)\right)}{E_{d}\left(0^{+}\right)}$ where, $L_{w}$ is the water-leaving radiance, $\rho$ represents the reflectance of the skylight from air-water interface which was considered as 0.028 (Mobley, 1999), and $E_{d}\left(0^{+}\right)$is the downwelling irradiance above water surface and is defined as:

$E_{d}\left(0^{+}\right)=L_{r e f}(\lambda) \pi f_{c}$

where, $f_{c}$ is the factory generated calibration coefficient of the reference panel.

For the Funil Reservoir, the field radiometric measurements were acquired during 2-5 April 2013 using the RAMSES hyperspectral radiometers (TriOS GmbH, Oldenburg, Germany) as described in Ogashawara et al. (2013). $E_{d}$ measures from the RAMSES hyperspectral radiometers were normalized (Eq. (10)) by the incident surface irradiance $\left(E_{S}\right)$ as proposed by Mueller (2000).

$E_{d}^{\prime}\left(z_{m}\right)=\frac{E_{d}\left(z_{m}\right) E_{s}\left(t\left(z_{1}\right)\right)}{E_{S}\left(t\left(z_{m}\right)\right)}$ 
where, $E_{d}^{\prime}\left(z_{m}\right)$ is the normalized downwelling irradiance at that depth $\left(z_{m}\right) ; E_{d}\left(z_{m}\right)$ is the original downwelling irradiance at depth $\left(z_{m}\right) ; E_{s}\left(t\left(z_{1}\right)\right)$ is the downwelling irradiance measured at time $t\left(z_{1}\right)$ and $E_{s}\left(t\left(z_{m}\right)\right)$ is the downwelling irradiance measured at time $t\left(z_{m}\right)$.

$R_{r s}$ was finally calculated based on Gitelson et al. (2009) using the calibrated $L_{u}$ and $E_{d}^{\prime}$ measures from the RAMSES hyperspectral radiometers (Eq. (11)).

$R_{r s}=\frac{t L_{u}\left(0^{-}\right)}{\pi n^{2} E_{d}^{\prime}\left(0^{+}\right)}$

where, $t$ is the water-to-air transmittance; $n$ is the refractive index of water relative to air and $\pi$ is used to transform the irradiance reflectance, $R$, into remote-sensing reflectance, $R_{r s}$.

The use of different methodologies and equipment for the computation of $R_{r s}$, did not change the intensity of the spectra (Fig. 2), however, there was noise (variation in the intensity of the spectrum) in the data from Itumbiara Reservoir - observed mostly in the blue and NIR region of the spectra. This is probably due to the fact that the data were acquired only from above the water using a sensor with a different integration time while in Funil Reservoir the data was also acquired under the air-water interface.

\subsection{Limnological variables}

The same methodology was followed for samples from both sites in deriving the concentrations of chl- $a$ and TSS during the laboratorial analysis. The water samples were stored in 1L Niskin opaque bottles at cool temperature until their delivery at the laboratory. For chl- $a$ concentration, water samples were filtered through Whatman GF/F filters and stored frozen $\left(-20^{\circ} \mathrm{C}\right)$ until further analysis. Filters were analyzed following Nush (1980) procedure which involved the extraction of chl-a pigment using $80 \%$ ethanol followed by a thermal shock of the substance before the absorbance reading using a U-3010 Hitachi (Hitachi, Tokyo, Japan) spectrophotometer. Concentrations were calculated according to Lorenzen (1967) protocol. TSS values were determined based on the procedure proposed by Wetzel and Likens (1991). This approach also used a filtering procedure of $1000 \mathrm{~mL}$ of water using a preashed (at $480^{\circ} \mathrm{C}$ ) and pre-weighed $\mathrm{GF} / \mathrm{C}$ filter. Filters were stored in desiccators over silica gel until the filtering procedure. In the laboratory, the filter was dried at $60^{\circ} \mathrm{C}$ for $24 \mathrm{~h}$ and weighed to determine TSS. The filters were calcined at $480^{\circ} \mathrm{C}$ for $1 \mathrm{~h}$ and reweighed to determine inorganic particle concentration for each sample. For Dissolved Organic Carbon (DOC) the concentrations were determined using an infrared detector on a total organic carbon analyzer (Shimadzu TOC-5000).

\subsection{Absorption coefficients estimates}

For the determination of $a_{C D O M}(\lambda)$, water samples were filtered immediately after collection, through a $0.2 \mu \mathrm{m}$ nucleopore membrane. Filtrates were stored in a cooler in amber color glass bottles till analysis in the laboratory. Filtered samples were allowed to reach ambient room temperature to minimize temperature bias between samples and blank (Milli-Q water) before absorption measurements. For Itumbiara Reservoir, $a_{C D O M}(\lambda)$ was measured from discrete samples using the high performance U-3010 Hitachi spectrophotometer with $10 \mathrm{~cm}$ quartz cells and within 300 and $750 \mathrm{~nm}$ range with $1 \mathrm{~nm}$ spectral resolution. For the Funil Reservoir, $a_{C D O M}(\lambda)$ was measured with a Lambda $35 \mathrm{UV} /$ Vis system in a transparent cuvette with Millipore Milli-Q water in the reference cell. The absorbance data were corrected for baseline fluctuations by subtracting the mean value from the absorbance of the Milli- $Q$ water measured at each wavelength (Mueller et al., 2002).

For the spectral absorption coefficients of particulate matter $\left(a_{p}(\lambda)\right), a_{\text {phy }}(\lambda), a_{N A P}(\lambda)$, water samples were collected in $1 \mathrm{~L}$
Niskin bottles. Samples were filtered onto $0.7 \mu \mathrm{m}$ Whatman GF/F filters. The volume of water filtered was $250 \mathrm{~mL}$ for all samples and their replicates. For the Itumbiara Reservoir, $a_{p}(\lambda)$ was determined using standard quantitative filtration technique (QFT) procedure as described in (Mueller et al., 2002). A UV-2450 Shimadzu spectrophotometer (Shimadzu Corporation, Kyoto, Japan) with an integrating sphere was used to scan the samples within a spectral range from 300 to $750 \mathrm{~nm}$. For Funil Reservoir, $a_{p}(\lambda)$ was measured using the filter pad method and Perkin Elmer Lambda 35 UV/Vis Systems spectrophotometer with a Perkin Elmer integrating sphere attachment following the method described by Tassan and Ferrari (1995). For the $a_{N A P}(\lambda)$ measurement in both study sites, samples were de-pigmented by soaking the filters in a $1 \%$ solution of sodium hypochlorite $(\mathrm{NaClO})$ to remove the phytoplankton pigments. The $a_{N A P}(\lambda)$ was measured by the same procedure followed for $a_{p}(\lambda)$ using the bleached filters. Further, $a_{p h y}(\lambda)$ was computed by subtracting $a_{N A P}(\lambda)$ from $a_{p}(\lambda)$. The absorption coefficient of $\operatorname{CDM}\left(a_{C D M}\right)$ was calculated by the sum of $a_{C D O M}(\lambda)$ and $a_{N A P}(\lambda)$.

\subsection{Error estimators}

To compare the QAAs and to evaluate the re-parameterized $\mathrm{QAA}_{\mathrm{CDOM}}$ for Itumbiara and Funil Reservoir, we calculated error estimators between the measure and estimated absorption coefficients. RMSE and NRMSE were calculated for accuracy assessment using Eqs. (12) and (13).

$R M S E=\sqrt{\frac{\sum_{i=1}^{N}\left(a_{\text {mea }}-a_{e s t}\right)^{2}}{N}}$

$$
\begin{aligned}
& \operatorname{NRMSE}(\%) \\
& =100\left(\sqrt{\frac{\sum_{i=1}^{N}\left(a_{\text {mea }}-a_{\text {est }}\right)^{2}}{N}} \cdot\left(a_{\text {mea }, \text { max }}-a_{\text {mea }, \text { min }}\right)^{-1}\right)
\end{aligned}
$$

where, $a_{\text {mea }}$ is the measured absorption coefficient; $a_{\text {est }}$ is the estimated absorption coefficient; $N$ is the number of samples; $a_{\text {mea,max }}$ is the maximum measured absorption coefficient; and $a_{\text {mea,min }}$ is the minimum measured absorption coefficient.

\section{Results and discussion}

\subsection{Environmental characteristics}

The limnological datasets collected from the water samples for the two study sites varied considerably as observed in the summary statistics (Table 2). For example, average chl- $a$ in Funil Reservoir was found to be $19.49(\mu \mathrm{g} / \mathrm{L})$, whereas, at the Itumbiara Reservoir, average chl- $a$ reading was 1.54 and $3.93(\mu \mathrm{g} / \mathrm{L})$ during May and September respectively (Table 2 ). Similar concentration differences between both study sites were observed for TSS, showing higher concentration in Funil Reservoir than in Itumbiara Reservoir. Average DOC concentrations also showed to be higher in Funil $(2.28 \mathrm{mg} / \mathrm{L})$, which was approximately twice higher than in Itumbiara Reservoir $(0.78$ and $1.16 \mathrm{mg} / \mathrm{L}$ for May and September campaign, respectively). These differences in concentrations were also observed in the standard deviation for each water quality parameter (Table 2). The standard deviation for chl- $a$ in Itumbiara Reservoir were 0.39 and 3.03 for May and September datasets, while in Funil Reservoir the chl-a standard deviation was 14.79. TSS standard deviation also showed the difference between the two datasets: 0.25 and 0.40 for the Itumbiara Reservoir and 1.22 for the Funil Reservoir. For the DOC data, the standard deviation also showed to be higher in Funil (0.99) than in Itumbiara Reservoir ( 0.15 and 0.32 , for May and September campaign, respectively). 
Table 2

Summary statistics of chl- $a$, TSS and DOC variables for the two study sites.

\begin{tabular}{|c|c|c|c|c|}
\hline & \multirow[b]{2}{*}{ Period } & \multicolumn{2}{|l|}{ Itumbiara } & \multirow{2}{*}{$\begin{array}{l}\text { Funil } \\
\text { April, } 2013(n=16)\end{array}$} \\
\hline & & May, $2009(n=25)$ & September, $2009(n=25)$ & \\
\hline \multirow[t]{5}{*}{ Chl- $a(\mu \mathrm{g} / \mathrm{L})$} & Minimum & 0.68 & 0.25 & 4.92 \\
\hline & Maximum & 2.70 & 10.02 & 52.78 \\
\hline & Range & 2.02 & 9.77 & 47.86 \\
\hline & Average & 1.54 & 3.93 & 19.49 \\
\hline & Standard Deviation & \pm 0.39 & \pm 3.03 & \pm 14.79 \\
\hline \multirow[t]{5}{*}{$\mathrm{TSS}(\mathrm{mg} / \mathrm{L})$} & Minimum & 0.6 & 0.25 & 4.50 \\
\hline & Maximum & 1.54 & 1.81 & 9.50 \\
\hline & Range & 0.94 & 1.56 & 5.00 \\
\hline & Average & 1.04 & 1.12 & 6.86 \\
\hline & Standard Deviation & \pm 0.25 & \pm 0.40 & \pm 1.22 \\
\hline \multirow[t]{5}{*}{$\mathrm{DOC}(\mathrm{mg} / \mathrm{L})$} & Minimum & 0.53 & 0.99 & 0.91 \\
\hline & Maximum & 1.17 & 2.59 & 6.30 \\
\hline & Range & 0.64 & 1.61 & 5.39 \\
\hline & Average & 0.78 & 1.16 & 2.28 \\
\hline & Standard Deviation & 0.15 & 0.32 & 0.99 \\
\hline
\end{tabular}

\subsection{Optical properties}

The differences in optical characteristics can also be noticed in the normalized $R_{r s}$ spectra collected as described in section 3.2 for Itumbiara and Funil Reservoirs (Fig. 2). $R_{r s}$ data from both study sites showed a peak in the green channel, at approximately $550 \mathrm{~nm}$, which is commonly due to the scattering from algal cells and relatively low absorption by chl- $a$ (Gitelson, 1992). Itumbiara Reservoir does not show any prominent signs of phytoplankton pigments, such as the absorption of chl- $a$ around $675 \mathrm{~nm}$ (Dall'Olmo and Gitelson, 2005) or the reflectance peak around $700 \mathrm{~nm}$ (Fig. 2A). These spectral features can be easily correlated to the environmental characteristics presented in Table 2, which showed that chl- $a$ concentrations were significantly different at both study sites with a much higher concentration at Funil Reservoir. Funil Reservoir, on the other hand, showed the spectral signs of another pigment, phycocyanin (PC) which could be observed by the narrow absorption feature around $620 \mathrm{~nm}$ (Fig. 2B; Simis et al., 2005) and by the reflectance peak at $650 \mathrm{~nm}$ caused by the prominent absorption on both sides, $620 \mathrm{~nm}$ (PC) and $670 \mathrm{~nm}$ (chl- $a$ ), and also because of the PC fluorescence maximum at around 640-660 nm (Mishra and Mishra, 2014; Mishra et al., 2009; Schalles and Yacobi, 2000). $R_{r s}$ data from Funil Reservoir also showed a strong phytoplankton presence because of the prominent $700 \mathrm{~nm}$ peak which appears due to the strong absorption on either side, by chl- $a$ at $675 \mathrm{~nm}$ and by water at $740 \mathrm{~nm}$ (Fig. 2B; Mishra and Mishra, 2012). Overall, the water quality parameters (chl- $a$ and TSS) at Itumbiara Reservoir was much lower compared to Funil Reservoir. This noticeable variance in the optical properties of these two reservoirs highlight the importance of developing a parameterization of a QAA, since the previous algorithms for inland waters (Mishra et al., 2013, 2014; Li et al., 2015) were calibrated and validated for in aquatic systems with similar optical properties.

IOPs such as the absorption coefficients were used to further differentiate optical properties of the water from both study sites. Fig. 3 shows a ternary plot of the absorption coefficients of phytoplankton, NAP, and CDOM at three different wavelengths: 443, 560, and $665 \mathrm{~nm}$ for each study sites. These wavelengths were chosen to fit MERIS spectral bands, as well as to fit the spectral features of CDOM, NAP and chl- $a$, respectively. In both ternary plots (Fig. $3 \mathrm{~A}$ and $\mathrm{B}), a_{\mathrm{CDOM}}$ is the dominant coefficient of absorption, mainly at the lower wavelengths. It was also observed that the points on the ternary plot were closer to the CDOM edge in the Funil Reservoir, which indicates that the dominance of $a_{C D O M}$ is higher in the Funil Reservoir (Fig. 3B) than in Itumbiara Reservoir (Fig. 3A). Table 3
Table 3

Standard deviation of the absorption coefficients for different spectral ranges.

\begin{tabular}{llllllll}
\hline & \multicolumn{2}{l}{ Itumbiara } & & & \multicolumn{2}{l}{ Funil } \\
\cline { 2 - 3 } Range $(\mathrm{nm})$ & $a_{\text {phy }}$ & $a_{\text {CDOM }}$ & $a_{\text {NAP }}$ & & $a_{\text {phy }}$ & $a_{\text {CDOM }}$ & $a_{\text {NAP }}$ \\
\hline $400-750$ & 0.013 & 0.070 & 0.026 & & 0.092 & 0.951 & 0.106 \\
$400-500$ & 0.003 & 0.066 & 0.014 & & 0.088 & 0.814 & 0.076 \\
$500-600$ & 0.006 & 0.013 & 0.009 & & 0.016 & 0.217 & 0.030 \\
$600-750$ & 0.007 & 0.003 & 0.003 & & 0.045 & 0.092 & 0.010
\end{tabular}

shows the standard deviation of absorption coefficients $\left(a_{p h y}, a_{C D O M}\right.$ and $a_{\text {NAP }}$ ) for different spectral ranges: $400-750 \mathrm{~nm}, 400-500 \mathrm{~nm}$, $500-600 \mathrm{~nm}$ and $600-750 \mathrm{~nm}$. These spectral ranges were selected to evaluate the performance of the algorithms for different spectral regions, such as: the visible and NIR, blue, green and red-NIR spectral ranges. For the Itumbiara Reservoir the standard deviation for the full spectral range $(400-750 \mathrm{~nm})$ showed higher value for $a_{C D O M}(0.07)$ compared to $a_{p h y}$ and $a_{N A P}$ at 0.013 and 0.026 respectively. A similar pattern in the IOPs for Funil Reservoir was observed where the standard deviation values for $a_{C D O M}$ was much higher (0.951) compared to $a_{p h y}$ and $a_{N A P}$ at 0.092 and 0.106 respectively. For the other spectral ranges, $a_{C D O M}$ consistently showed the highest values in Funil Reservoir, however, in Itumbiara Reservoir the range 600-750 nm showed that $a_{\text {phy }}$ was the dominant coefficient (Table 3 ). Although there is a significant difference in $a_{\text {phy }}$ between both datasets, the IOP analysis suggests that both reservoirs can be classified as CDOM dominated. $a_{C D O M}$ was the dominant optical property for Funil Reservoir in all spectral ranges analyzed in this study (Table 3 ). For Itumbiara Reservoir, $a_{C D O M}$ was the dominant optical property in most of the wavelength ranges except for the $600-750 \mathrm{~nm}$ range, which is usually characterized by the low absorption of CDOM. Therefore, both reservoirs in a way are very different from the water bodies used for the development of recent QAAs, such as: open ocean waters with $a_{p h y}$ dominance (Lee et al., 2002), hypereutrophic catfish ponds with $a_{p h y}$ dominance (Mishra et al., 2014), and mesotrophic reservoirs with $a_{p h y}$ dominance (Li et al., 2015).

\subsection{QAAs comparison}

To check the accuracy of existing variants of QAA in CDOM dominated waters, performance of three different QAAs: $\mathrm{QAA}_{\mathrm{L} 09}$ (Lee et al., 2009), QAA $\mathrm{M}_{14}$ (Mishra et al., 2014) and $\mathrm{QAA}_{\mathrm{L} 15}$ (Li et al., 2015), were assessed by using the Funil Reservoir dataset which showed to be the most dominated by CDOM. This dataset also 
A)

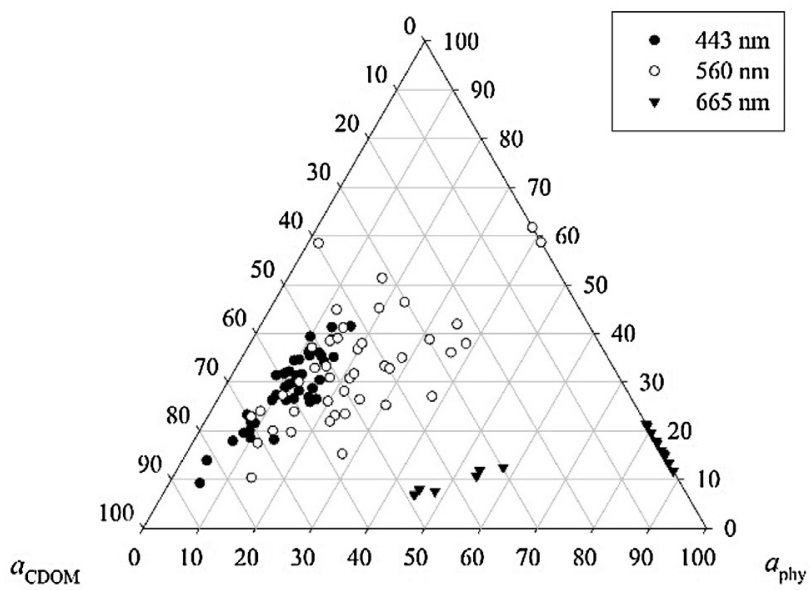

B)

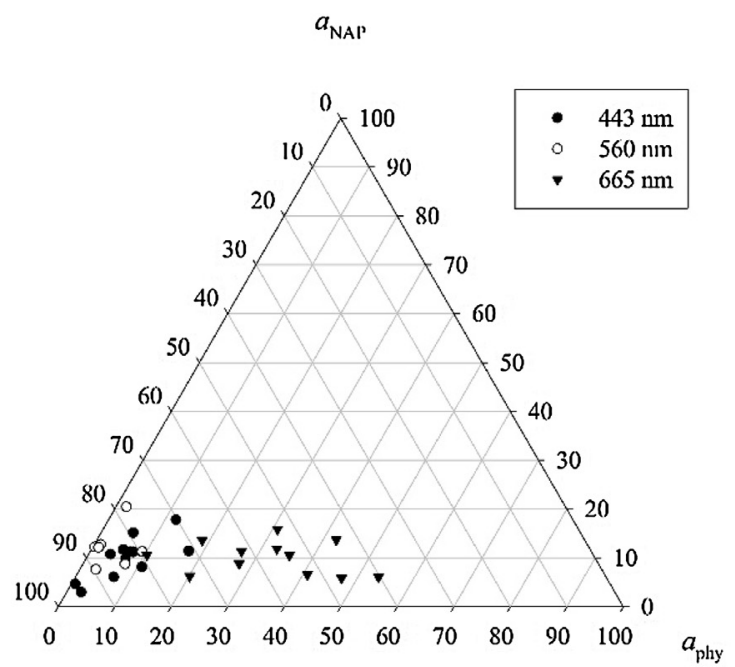

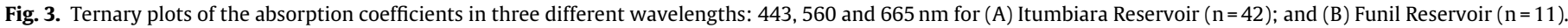
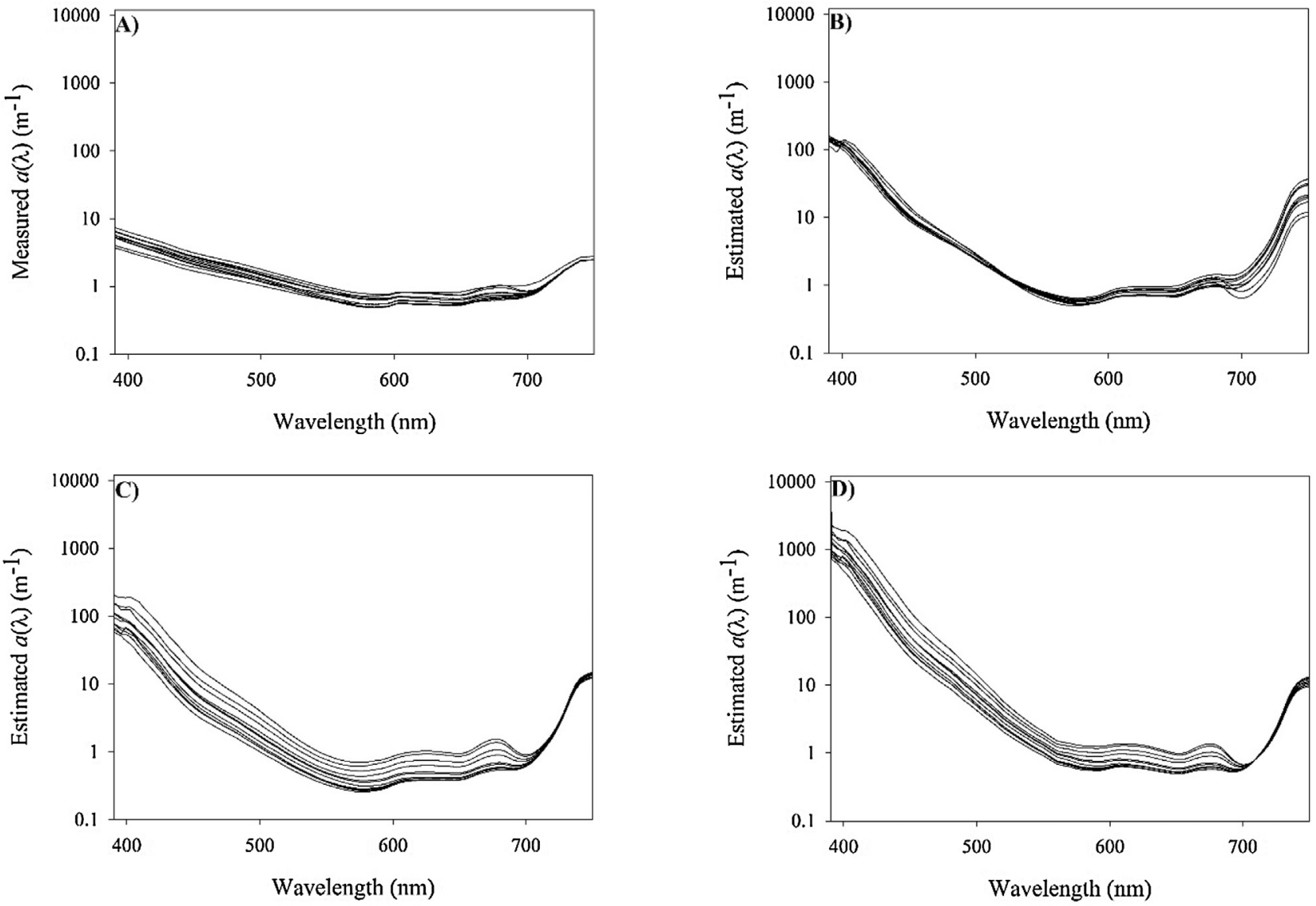

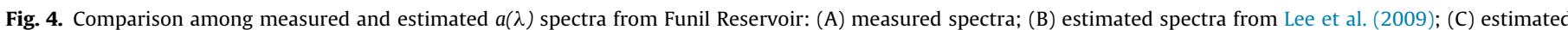
spectra from Mishra et al. (2014); and estimated spectra from Li et al. (2015).

showed high variance in the values of $a(\lambda)$ from the visible to the NIR spectral regions, which is ideal to assess the potential of the algorithms. The estimation accuracy of $a(\lambda)$ from the three QAAs is shown on Fig. 4. The reference $a(\lambda)$ measured in the laboratory from the filter pad method (Fig. 4A) is compared to the estimated $a(\lambda)$ spectra from: $\mathrm{QAA}_{\mathrm{L} 09}$ (Fig. 4B), QAA $\mathrm{M}_{14}$ (Fig. 4C), and $\mathrm{QAA} \mathrm{L}_{\mathrm{L} 15}$ (Fig. 4D). $a(\lambda)$ values are presented in logarithmic scale for comparison of all three algorithms output in terms of shape and intensity.
Results show that all three QAAs failed to retrieve an accurate overall spectra of $a(\lambda)$, overestimating the $a(\lambda)$ values mainly in the blue spectral range. The average RMSE and NRMSE were computed for each model (Table 4) using Funil dataset in four different spectral ranges: $400-750 \mathrm{~nm}, 400-500 \mathrm{~nm}, 500-600 \mathrm{~nm}$, and $600-750 \mathrm{~nm}$. The estimation accuracy of $a(\lambda)$ for the $400-750 \mathrm{~nm}$ range was relatively higher using $\mathrm{QAA}_{\mathrm{M} 14}$ with an NRMSE of $389.96 \%$ compared to $\mathrm{QAA}_{\mathrm{L} 09}(499.78 \%)$ and $\mathrm{QAA} \mathrm{L}_{\mathrm{L} 15}(4077.71 \%)$. However, $\mathrm{QAA} \mathrm{A}_{\mathrm{M} 14}$ 
Table 4

Average RMSE and NRMSE comparison among the three QAAs evaluated.

\begin{tabular}{|c|c|c|c|c|}
\hline & & Lee et al. (2009) & Mishra et al. (2014) & Li et al. (2015) \\
\hline$a(400-750 \mathrm{~nm})$ & $\begin{array}{l}\text { RMSE }\left(\mathrm{m}^{-1}\right) \\
\operatorname{NRMSE}(\%)\end{array}$ & $\begin{array}{l}19.95 \\
499.78\end{array}$ & $\begin{array}{l}16.27 \\
389.96\end{array}$ & $\begin{array}{l}169.53 \\
4077.71\end{array}$ \\
\hline$a(400-500 \mathrm{~nm})$ & $\begin{array}{l}\text { RMSE }\left(\mathrm{m}^{-1}\right) \\
\text { NRMSE (\%) }\end{array}$ & $\begin{array}{l}36.62 \\
1120.71\end{array}$ & $\begin{array}{l}30.17 \\
885.58\end{array}$ & $\begin{array}{l}317.59 \\
9356.60\end{array}$ \\
\hline$a(500-600 \mathrm{~nm})$ & $\begin{array}{l}\operatorname{RMSE}\left(\mathrm{m}^{-1}\right) \\
\operatorname{NRMSE}(\%)\end{array}$ & $\begin{array}{l}0.45 \\
63.42\end{array}$ & $\begin{array}{l}0.33 \\
46.30\end{array}$ & $\begin{array}{l}2.05 \\
277.89\end{array}$ \\
\hline$a(600-750 \mathrm{~nm})$ & $\begin{array}{l}\text { RMSE }\left(\mathrm{m}^{-1}\right) \\
\text { NRMSE (\%) }\end{array}$ & $\begin{array}{l}5.33 \\
280.20\end{array}$ & $\begin{array}{l}3.09 \\
164.91\end{array}$ & $\begin{array}{l}2.51 \\
133.67\end{array}$ \\
\hline$a_{C D M}(400-750 \mathrm{~nm})$ & $\begin{array}{l}\text { RMSE }\left(\mathrm{m}^{-1}\right) \\
\text { NRMSE (\%) }\end{array}$ & $\begin{array}{l}42.63 \\
1019.59\end{array}$ & $\begin{array}{l}35.51 \\
820.27\end{array}$ & $\begin{array}{l}1.74 \\
39.74\end{array}$ \\
\hline$a_{C D M}(400-500 \mathrm{~nm})$ & $\begin{array}{l}\text { RMSE }\left(\mathrm{m}^{-1}\right) \\
\operatorname{NRMSE}(\%)\end{array}$ & $\begin{array}{l}78.86 \\
2650.41\end{array}$ & $\begin{array}{l}65.75 \\
2145.32\end{array}$ & $\begin{array}{l}2.95 \\
94.06\end{array}$ \\
\hline$a_{C D M}(500-600 \mathrm{~nm})$ & $\begin{array}{l}\operatorname{RMSE}\left(\mathrm{m}^{-1}\right) \\
\operatorname{NRMSE}(\%)\end{array}$ & $\begin{array}{l}12.35 \\
1515.93\end{array}$ & $\begin{array}{l}10.08 \\
1188.75\end{array}$ & $\begin{array}{l}1.14 \\
135.95\end{array}$ \\
\hline$a_{C D M}(600-750 \mathrm{~nm})$ & $\begin{array}{l}\text { RMSE }\left(\mathrm{m}^{-1}\right) \\
\operatorname{NRMSE}(\%)\end{array}$ & $\begin{array}{l}1.38 \\
389.87\end{array}$ & $\begin{array}{l}1.04 \\
270.29\end{array}$ & $\begin{array}{l}0.57 \\
156.11\end{array}$ \\
\hline$a_{p h y}(400-750 \mathrm{~nm})$ & $\begin{array}{l}\text { RMSE }\left(\mathrm{m}^{-1}\right) \\
\text { NRMSE }(\%)\end{array}$ & $\begin{array}{l}27.63 \\
10452.45\end{array}$ & $\begin{array}{l}23.04 \\
7566.33\end{array}$ & $\begin{array}{l}170.66 \\
57763.24\end{array}$ \\
\hline$a_{p h y}(400-500 \mathrm{~nm})$ & $\begin{array}{l}\operatorname{RMSE}\left(\mathrm{m}^{-1}\right) \\
\operatorname{NRMSE}(\%)\end{array}$ & $\begin{array}{l}49.67 \\
24393.92\end{array}$ & $\begin{array}{l}41.65 \\
17954.46\end{array}$ & $\begin{array}{l}319.71 \\
142107.1\end{array}$ \\
\hline$a_{p h y}(500-600 \mathrm{~nm})$ & $\begin{array}{l}\text { RMSE }\left(\mathrm{m}^{-1}\right) \\
\operatorname{NRMSE}(\%)\end{array}$ & $\begin{array}{l}12.39 \\
22852.78\end{array}$ & $\begin{array}{l}10.43 \\
16793.26\end{array}$ & $\begin{array}{l}2.74 \\
4726.80\end{array}$ \\
\hline$a_{p h y}(600-750 \mathrm{~nm})$ & $\begin{array}{l}\text { RMSE }\left(\mathrm{m}^{-1}\right) \\
\operatorname{NRMSE}(\%)\end{array}$ & $\begin{array}{l}5.52 \\
5327.63\end{array}$ & $\begin{array}{l}3.34 \\
2804.82\end{array}$ & $\begin{array}{l}2.54 \\
2263.63\end{array}$ \\
\hline
\end{tabular}

did not performed consistently better for all spectral ranges, for $600-750 \mathrm{~nm}$ range, $\mathrm{QAA}_{\mathrm{L} 15}$ produced a lower NRMSE (133.67\%). These variations in the performances among the three algorithms pointed to the fact that the ones developed for inland waters $\left(\mathrm{QAA}_{\mathrm{M} 14}\right.$ and $\left.\mathrm{QAA} \mathrm{L}_{\mathrm{L} 15}\right)$ have an advantage over the ones developed for ocean and coastal waters $\left(\mathrm{QAA}_{\mathrm{LO}}\right)$. However, overall errors in $a(\lambda)$ estimation by all three algorithms were too high and unacceptable for our study sites. It was concluded that none of the QAAs were able to accurately estimate $a(\lambda)$ and produced some of the highest errors in the range between 400 and $500 \mathrm{~nm}$ which happens to be the major CDOM absorption band indicating that these models should not be used in their current form to retrieve IOPs in CDOM dominated waters. The comparatively better performance of $Q A A_{L 15}$ for the 600-750 nm range can be related to the fact that $a(\lambda)$ derived from $\mathrm{QAA}_{\mathrm{L} 15}$ is actually the non-water absorption coefficient $\left(a_{t-w}\right)$. Therefore, $a(\lambda)$ for QAA $\mathrm{L}_{\mathrm{L} 15}$ was computed as the sum of $a_{t-w}$ and pure water absorption coefficient $\left(a_{w}\right) . a_{w}$ was $(\lambda)$ obtained by linearly interpolating the data presented in Pope and Fry (1997) for the range of 380-730 nm and Smith and Baker (1981) to complete the data until $750 \mathrm{~nm}$ to calculate the total absorption coefficient by the sum of all other absorption coefficients.

Since in a QAA, $a(\lambda)$ is decomposed to retrieve $a_{C D M}(\lambda)$ and $a_{p h y}(\lambda)$, the estimation of $a_{C D M}(\lambda)$ from the three selected QAAs were also compared (Fig. 5). The measured $a_{C D M}(\lambda)$ in the Funil Reservoir (Fig. 5A) was plotted against the estimated $a_{C D M}(\lambda)$ from $\mathrm{QAA}_{\mathrm{L} 09}$ (Fig. 5B), QAA $\mathrm{M} 14_{\text {(Fig. 5C), and } \mathrm{QAA}}$ 15 (Fig. 5D). QAA $\mathrm{L}_{\mathrm{L} 9}$ and $\mathrm{QAA}_{\mathrm{M} 14}$ showed estimated $a_{C D M}(\lambda)$ spectra ten times higher than the measured one, whereas $Q A A_{L 15}$ significantly underestimated $a_{C D M}(\lambda)$. Besides these differences in the magnitude of the spectra, it was observed that the three algorithms computed the same shape, a decreasing value from lower to higher wavelengths. The lowest NRMSE value for the full range (from 400 to $750 \mathrm{~nm}$ ) was produced by $\mathrm{QAA}_{\mathrm{L} 15}$ (39.75\%). This algorithm also showed a better performance among the three tested QAAs for the other spectral ranges with NRMSE of $94.06 \%, 135.95 \%$ and $156.11 \%$ for
$400-500 \mathrm{~nm}, 500-600 \mathrm{~nm}$ and $600-750 \mathrm{~nm}$ respectively (Table 4). Although the comparative performance by $\mathrm{QAA}_{\mathrm{L} 15}$ was better than the other QAAs for $a_{C D M}(\lambda)$, NRMSE for shorter spectral ranges were still close to $100 \%$ error which is not acceptable. Moreover, QAA $A_{\mathrm{L} 15}$ showed that there is not a large variance from low to high wavelengths, which is the opposite of the measured $a_{C D M}(\lambda)$ (Fig. $5 \mathrm{~A}$ ), therefore $\mathrm{QAA}_{\mathrm{L} 15}$ is not suitable for estimation of $a_{C D M}(\lambda)$. The difference in intensity between $\mathrm{QAA}_{\mathrm{L} 15}$ and the other two QAAs, is based on the fact that $\mathrm{QAA}_{\mathrm{L} 15}$ does not estimate $a_{C D M}(\lambda)$ from $a(\lambda)$, but from the subtraction between $a_{t-w}$ and the absorption coefficient of chlorophyll $\left(a_{c h l-a}\right)$. Li et al. (2015) introduced two constants in the accurate estimation of $a_{c h l-a}$, however, the estimation of $a_{C D M}(\lambda)$ by the model was not able to detect the variation of CDOM. Thus, although NRMSE showed that $\mathrm{QAA}_{\mathrm{L} 15}$ had the best performance, it failed in the identification of $a_{C D M}(\lambda)$ variance and intensity, therefore, none of the algorithms were able to retrieve $a_{C D M}(\lambda)$ from Funil Reservoir.

$a_{\text {phy }}(\lambda)$ predicted by the three QAAs were also analyzed (Fig. 6) by comparing the measured spectra (Fig. $6 \mathrm{~A}$ ) to the spectra estimated from QAA $\mathrm{L}_{09}$ (Fig. 6B), QAA $\mathrm{M}_{14}$ (Fig. 6C), and QAA $\mathrm{L}_{\mathrm{L} 15}$ (Fig. 6D). Visually it is clear to observe that none of the QAAs were able to retrieve $a_{p h y}(\lambda)$ accurately. QAA $\mathrm{L}_{\mathrm{L} 9}$ and QAA $\mathrm{A}_{\mathrm{M} 14}$ produced similarly shaped $a_{\text {phy }}(\lambda)$ spectra (Fig. $6 \mathrm{~B}$ and $\mathrm{C}$ ), but they were very different in magnitude compared to the measured $a_{\text {phy }}(\lambda)$ (Fig. 6A). The shape of the $a_{p h y}(\lambda)$ produced by $\mathrm{QAA}_{\mathrm{L} 15}$ (Fig. 6D) was completely different when compared to the lab data and other two QAAs, which could be related to the structural difference in $\mathrm{QAA}_{\mathrm{L} 15}$ design, as it considered that at $665 \mathrm{~nm}$ the in vitro phytoplankton absorption coefficient $\left(a_{\text {sol }}\right)$ is the only absorption coefficient in this wavelength. Other differences is that $\mathrm{QAA}_{\mathrm{L} 15}$ does not calculate $a$, but instead it calculates $a_{t-w}(\lambda)$. Due to these differences compared to the QAAs developed based on Lee et al. (2002) algorithm, the shape is different than the ones produced by $\mathrm{QAA}_{\mathrm{L} 09}$ and $\mathrm{QAA} \mathrm{A}_{\mathrm{M} 14}$. Nevertheless, $\mathrm{QAA}_{\mathrm{L} 09}$ and $\mathrm{QAA} \mathrm{A}_{\mathrm{M} 14}$ were not able to estimate $a_{\text {phy }}(\lambda)$ accurately either; both showed negative values and a shape that 

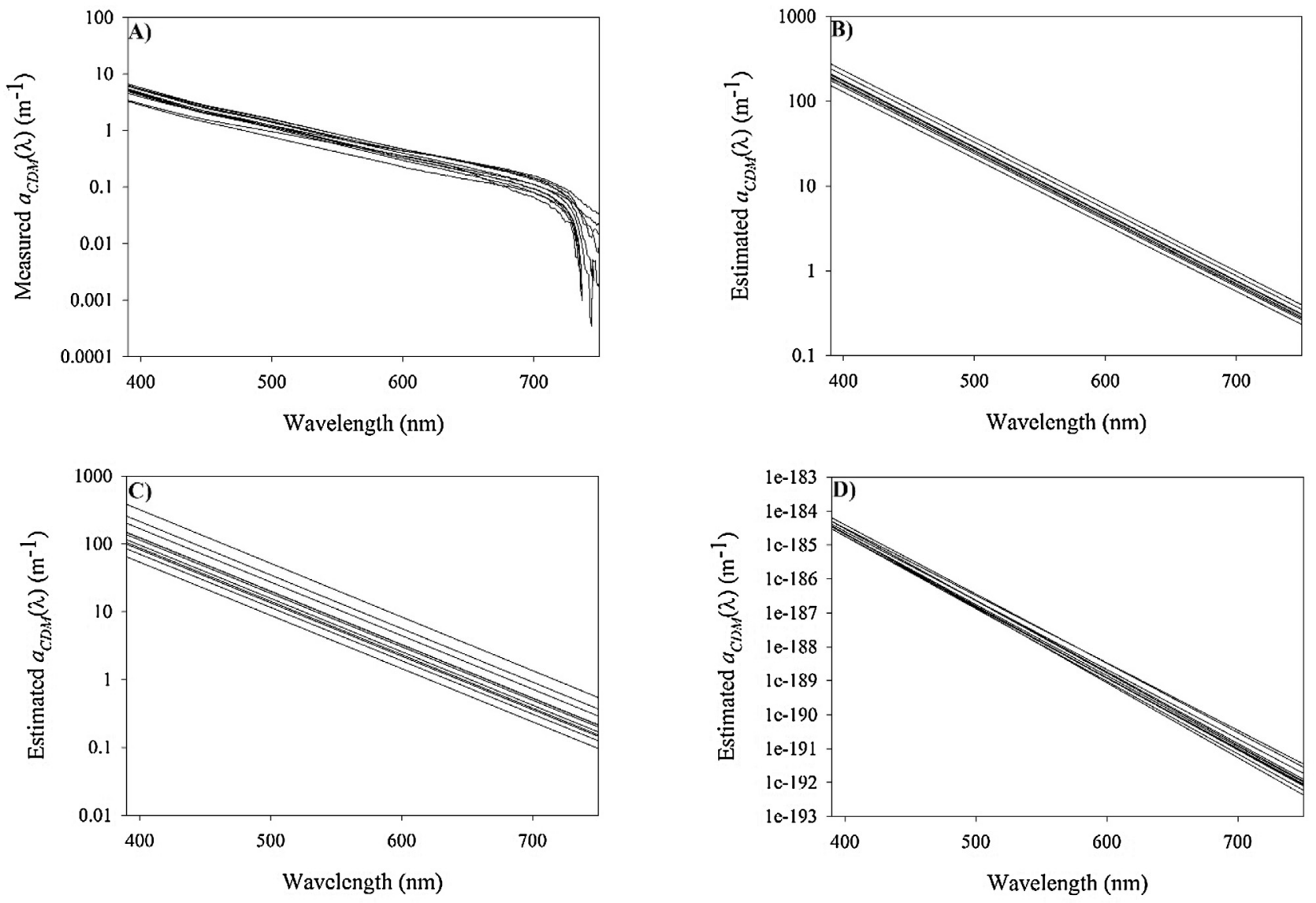

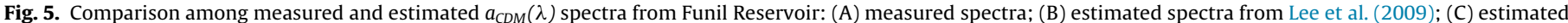
spectra from Mishra et al. (2014); and (D) estimated spectra from Li et al. (2015).

is completely different from the reference (Fig. 6A). This can be explained by the structure used to calculate $a_{\text {phy }}(\lambda)$, which is based on the subtraction of $a_{C D M}(\lambda)$ from the $a(\lambda)$. Since the estimation of both absorption coefficients showed problems, the estimation of $a_{p h y}(\lambda)$ will not be accurate.

The performance of the three algorithms in retrieving $a_{p h y}(\lambda)$ in Funil Reservoir were tested for different wavelength ranges: $400-750 \mathrm{~nm}, 400-500 \mathrm{~nm}, 500-600 \mathrm{~nm}$ and 600-750 nm (Table 4). The lowest NRMSE among the QAAs was $2263.63 \%$ which indicated that none of the algorithms were able to accurately retrieve $a_{p h y}(\lambda)$. These results highlight the need for a re-parameterization of a QAA for CDOM dominated sites such as Funil and Itumbiara reservoirs. Since the absorption coefficients of the OACs in QAA are derived from $a(\lambda)$, its estimation is important to the performance of the algorithm. The comparative analysis showed that all algorithms were overestimating $a(\lambda)$, mainly in the $400-500 \mathrm{~nm}$ range, the dominant CDOM absorption band. Since several watersheds have a well-developed soil which is usually rich in organic matter, it is important to account for the influence of CDOM in the water column. This assessment will also help improve the estimation accuracies of $a_{p h y}(\lambda)$ and $a_{N A P}(\lambda)$ in these type of waters. Based on the results from the comparative analysis, the models originally developed for inland waters (Mishra et al., 2014; Li et al., 2015) showed better performance than $\mathrm{QAA}_{\mathrm{L} 09}$ which was developed for coastal/oceanic waters. $\mathrm{QAA}_{\mathrm{M} 14}$ algorithm showed the best performance to retrieve $a(\lambda)$, therefore, it was used as a starting point to re-parameterize the algorithm for CDOM dominated tropical reservoirs referred to as $\mathrm{QAA}_{\mathrm{CDOM}}$ hereafter.

\subsection{QAA model inversion}

\subsubsection{Re-parameterization}

The $\mathrm{QAA}_{\mathrm{CDOM}}$ for CDOM dominated waters follows the mathematical steps of the algorithm proposed by Mishra et al. (2014). Therefore, the derivation of IOPs starts with the transformation of $R_{r s}$ to $r_{r s}$ as shown below:

$r_{r s}(\lambda)=\frac{R_{r s}(\lambda)}{\left(0.52+1.7 R_{r s}(\lambda)\right)}$

$r_{r s}$ is then used to calculate $u$, as follows:

$u(\lambda)=\frac{-g_{0} \sqrt{\left(g_{0}\right)^{2}+4 g_{1} \cdot r_{r s}(\lambda)}}{2 g_{1}}$

where: $g_{0}$ and $g_{1}$ are constant with values of 0.089 and 0.125 respectively (Mishra et al., 2014).

Further, the QAA $A_{\mathrm{CDOM}}$ estimates $a\left(\lambda_{0}\right)$ following Eq. (16). In this study, we used $560 \mathrm{~nm}$ as reference wavelength $\left(\lambda_{0}\right)$ in (Eq. (16)) and the exponent values from Lee et al. (2009). The choice for the use of the traditional $560 \mathrm{~nm}$ as the $\lambda_{0}$, instead of $709 \mathrm{~nm}$ (Mishra et al., 2014) was based on the fact that at this wavelength the inference of IOPs, mainly $a_{C D O M}(\lambda)$, is minimized (Babin et al., 2003). Moreover, Mishra et al. (2014) did not observe a drastic improvement when the $\lambda_{0}$ moved to $709 \mathrm{~nm}$.

$a\left(\lambda_{0}\right)=a_{w}(\lambda)+10^{-1.146-1.366 \chi-0.469 \chi^{2}}$

where, $\chi$ is calculated by Eq. (17) which uses the spectral bands matching with the Medium Resolution Imaging Spectrometer (MERIS) and upcoming Sentinel-3's Ocean Land Color Instrument 

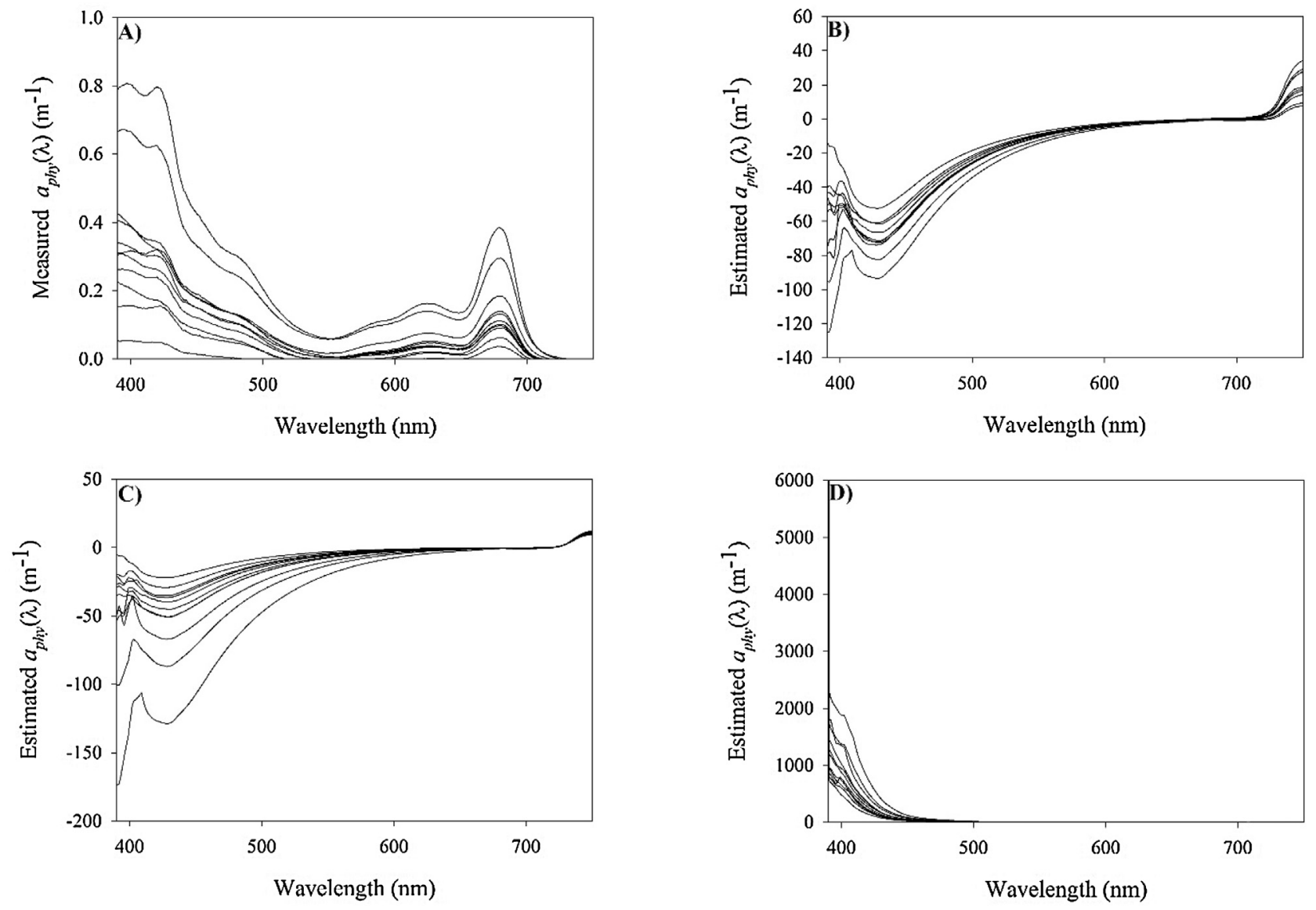

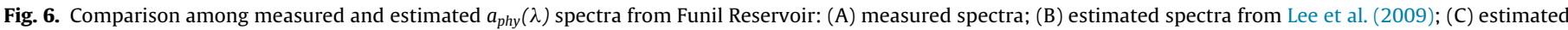
spectra from Mishra et al. (2014); and estimated spectra from Li et al. (2015).

(OLCI). Eq. (17) follows the structure from QAA_v5 (Lee et al., 2009), however, few changes were made to emphasize the CDOM effect on the water, for example, $r_{r s}$ at $412 \mathrm{~nm}$ was used instead of $443 \mathrm{~nm}$ due to the higher absorption of CDOM at lower wavelengths (Kutser et al., 2005) and absorption peak of phytoplankton around $443 \mathrm{~nm}$ (Ciotti et al., 1999). Moreover, the $r_{r s}$ at $560 \mathrm{~nm}$ was added in the numerator to compensate for the variability introduced by CDOM absorption on $r_{r s}$, while in the numerator, the values were based on the chl- $a$ absorption at 443 and $665 \mathrm{~nm}$.

$\chi=\log \left(\frac{r_{r s}(412)+r_{r s}(560)}{r_{r s}\left(\lambda_{0}\right)+5 \frac{r_{r s}(665)}{r_{r s}(443)} r_{r s}(665)}\right)$

The QAA then analytically retrieved $b_{b p}\left(\lambda_{0}\right)$, as described in Lee et al. (2002).

$b_{b p}\left(\lambda_{0}\right)=\frac{u\left(\lambda_{0}\right) a\left(\lambda_{0}\right)}{1-u\left(\lambda_{0}\right)}-b_{w}\left(\lambda_{0}\right)$

where, $u\left(\lambda_{0}\right)$ was derived from Eq. (15), $a\left(\lambda_{0}\right)$ was derived from Eq. (16), and $b_{w}\left(\lambda_{0}\right)$ was used as given in Morel (1974).

The $b_{b}(\lambda)$ was then calculated (Eq. (19)) as given in Lee et al. (2009):

$b_{b}(\lambda)=b_{b, w}(\lambda)+b_{b, p}\left(\lambda_{0}\right)\left(\frac{\lambda_{0}}{\lambda}\right)^{\eta}$

where, $\eta$ is the spectral power for backscattering coefficient and calculated based on Mishra et al. (2014) as:

$\eta=2\left(1-1.2 \exp \left(-0.9 \frac{r_{r s}(443)}{r_{r s}\left(\lambda_{0}\right)}\right)\right)$ $a(\lambda)$ was computed using a modified step from Lee et al. (2002). We observed that the magnitude of $a(\lambda)$ estimated using the QAAs based on Lee et al. (2002) were overestimated with a magnitude order of 10-100 times higher than the measured spectra (Fig. 4). Therefore, in $\mathrm{QAA}_{\mathrm{CDOM}}$, we added a factor to compute the influence of CDOM based on a blue-green ratio $\left(C_{1}\right)$, as shown in Eq. (21).

$a(\lambda)=\frac{\left(c_{1}-u(\lambda)\right)\left(b_{b, w}(\lambda)+b_{b}(\lambda)\right)}{u(\lambda)}$

where, $C_{1}$ is the factor that computes the CDOM influence in the water column and is calculated by the ratio between the $r_{r s}(443)$ and $r_{r s}(560)\left(\left(r_{r s}(443) / r_{r s}(560)\right)\right.$ which exploits the differential absorption of CDOM at those two bands, high at $443 \mathrm{~nm}$ and low at $560 \mathrm{~nm}$ (Babin et al., 2003). In CDOM dominated waters $C_{1}$ will be lower compared to other waters, since it has a higher absorption at $443 \mathrm{~nm}$ compared to $560 \mathrm{~nm}$. The use of $C_{1}$ as a variable instead of a constant (1.0 in Eq. (3)), will reduce the magnitude of $b_{b}(\lambda)$ for CDOM dominated waters, and consequently reduce the estimation magnitude of $a(\lambda)$ which was significantly overestimated by the other QAAs (Fig. 4). The reduction in the magnitude of $b_{b}(\lambda)$ can be explained by the absorption due to CDOM, which is noticeable even at the higher wavelengths for our study sites (Fig. 3). Thus, applying $C_{1}$ to reduce the value of $b_{b}(\lambda)$ may lower the uncertainly associated with $a_{C D O M}$ estimation for the entire spectrum and increase the estimation accuracy of $a(\lambda)$ which is crucial for further spectral decomposition to retrieve other IOPs.

From the total absorption spectrum, $\mathrm{QAA}_{\mathrm{CDOM}}$ was further decomposed into $a_{C D M}(\lambda)$ which is the combined absorption by 
CDOM and NAP. $a_{C D M}(\lambda)$ can be calculated by using the power spectral slope as described in Lee et al. (2009) in Eq. (22).

$a_{C D M}(\lambda)=a_{C D M}\left(\lambda_{0}\right) e^{-S(\lambda-443)}$

where, $S$ was calculated using Eq. (23) and $a_{C D M}\left(\lambda_{0}\right)$ was calculated using Eq. (24) as:

$S=0.015+\frac{0.002}{0.6+r_{r S}(443) / r_{r S}\left(\lambda_{0}\right)}$

$a_{C D M}\left(\lambda_{0}\right)=\frac{\left(a(412)-\zeta a\left(\lambda_{0}\right)\right)-\left(a_{w}(412)-\zeta a_{w}(412)\right)}{\xi-\zeta}$

where,

$\zeta=0.74+\frac{0.2}{0.8+r_{r s}(443) / r_{r s}(0)}$

$\xi=e^{S(443-412)}$

The estimation of $a_{p h y}(\lambda)$ using the other QAAs was highly erroneous mainly because of the fact that Funil and Itumbiara waters were not phytoplankton dominated. Therefore, since $a_{\text {phy }}$ was not the dominant IOP, an algorithm that considered the phytoplankton spectral features was used. $a_{p h y}(\lambda)$ was modeled based on Lee et al. (2010) which uses a normalized phytoplankton absorption coefficient $\left(a^{+}{ }_{\text {phy }}(\lambda)\right)$ to provide the spectral shape of $a_{\text {phy }}(\lambda)$. Since the work by Lee et al. (2010) was conducted in a phytoplankton dominated environment, for the application of their algorithm in CDOM dominated waters, it is necessary to correct the influence of CDOM in the water column. Therefore, a factor $\left(C_{2}\right)$ based on the spectral responses of CDOM and chl- $a$ was incorporated to the algorithm to increase the estimation accuracy of $a_{p h y}(\lambda)$ (Eq. (27)).

$a_{p h y}(\lambda)=a_{p h y}\left(\lambda_{0}\right) a_{p h y}^{+}(\lambda) \cdot C_{2}$

where, $a_{\text {phy }}\left(\lambda_{0}\right)$ can be calculated from Eq. (28); and $a^{+}{ }_{p h y}(\lambda)$ was obtained from Roesler et al. (1989) and $C_{2}$ is the correction for CDOM which is calculated by the absolute ratio between the $a(665)$ and $a(412)$ multiplied by 10 :

$C_{2}$ is sensitive to the absorption at $665 \mathrm{~nm}$ which is purely from phytoplankton and at $412 \mathrm{~nm}$ which is mainly from CDOM. Since the values of $R_{r s}$ at $412 \mathrm{~nm}$ would be lower than at $665 \mathrm{~nm}$ in CDOM dominated environments, $C_{2}$ can be used to approximate the influence of CDOM in the computation of $a_{\text {phy }}\left(\lambda_{0}\right)$. If chl- $a$ concentration is higher, the ratio tends to be lower or equals to 1 , which prevents overestimation of the $a_{\text {phy }}(\lambda)$ and vice versa. The multiplication factor of 10 used in the calculation of $C_{2}$, is to correct the $a^{+}$phy $(\lambda)$ from Roesler et al. (1989) which varied from -0.006 to 0.027 . This factor is then used to correct the interference of CDOM on $a_{p h y}(\lambda)$ estimation.

$a_{p h y}\left(\lambda_{0}\right)=\frac{(\xi a(560)-a(412))-\left(\xi a_{w}(560)-a_{w}(412)\right)}{\xi-\zeta}$

In summary, the major modifications in the $\mathrm{QAA}_{\mathrm{CDOM}}$ compared to $\mathrm{QAA}_{\mathrm{L} 09}$ are: (i) the use of $560 \mathrm{~nm}$ as the $\lambda_{0}$; (ii) adjustments in the wavelengths to fit MERIS and OLCI spectral bands in Eq. (17); (iii) the use of $C_{1}$ to correct for the CDOM effect on $a(\lambda)$ estimation; (iv) the computation of $a_{\text {phy }}(\lambda)$ based on Lee et al. (2010); (v) the use of $C_{2}$ to correct the CDOM interference on $a_{p h y}(\lambda)$ estimation.

\subsubsection{Retrieval of $a(\lambda)$}

Measured and QAA ${ }_{\mathrm{CDOM}}$ estimated $a(\lambda)$ spectra were compared for Funil and Itumbiara Reservoirs (Fig. 7). Measured $a(\lambda)$ from Funil Reservoir showed high absorption in the blue spectral range, mainly caused by the high abundance of CDOM and a moderate absorption in the NIR range due to the absorption by pure water (Fig. 7A). For the Itumbiara Reservoir, the measured $a(\lambda)$ showed a moderate absorption in the blue range and a high peak in the
NIR wavelengths both caused by CDOM and pure water absorptions respectively (Fig. 7B). QAA $\mathrm{CDOM}_{\mathrm{M}}$ was able to retrieve $a(\lambda)$ and achieve similar shape for both Funil (Fig. 7C) and Itumbiara (Fig. 7D) datasets, with a high absorption in the blue spectral range for Funil and in the NIR range for Itumbiara Reservoir. The magnitude of QAA ${ }_{C D O M}$ estimated $a(\lambda)$ which was highly overestimated by the existing QAAs for inland waters (Fig. 4) were similar to the measured $a(\lambda)$ in the range of $450-650 \mathrm{~nm}$. Comparing the measured and estimated spectra, $\mathrm{QAA} \mathrm{ADOM}_{\mathrm{CD}}$ slightly underestimated the magnitude of $a(\lambda)$ which is probably related to the calculation of $u(\lambda)$ and the values of $g_{0}$ and $g_{1}$ (Fig. 7A-D). These values are empirically derived and are related to the directional nature of the light distribution factor $(Q)$, and the geometrical light factor $(f)$ which links the magnitude of the irradiance reflectance to the IOPs. Aurin and Dierssen (2012) showed that the tuning of $g_{0}$ and $g_{1}$ improve the retrieval of IOPs, therefore, the underestimation could be related to the use of fixed values of $g_{0}$ and $g_{1}$. The adoption of these fixed values in the $\mathrm{QAA} \mathrm{ADOM}_{\mathrm{CDO}}$ is justified to avoid the need of empirical tuning to compute the IOPs. If it is successfully validated, the utilization of the algorithm without an empirical tuning can be used to retrieve information from places where we do not have any background information, therefore it can be used as an operational method. The relationship between estimated and measured $a(\lambda)$ for Funil and Itumbiara reservoirs also showed a systematic underestimation, in most cases, with the trend line parallel to the 1:1 line (Figs. 7E and 7F). However, when compared to other QAAs (Fig. 4), the QAA ${ }_{C D O M}$ could appropriately retrieve not only the shape but also the magnitude of the spectra. RMSE and NRMSE values for QAA $\mathrm{CDOM}_{\text {in Funil }}$ and Itumbiara Reservoir (Table 5), compared to the values from other QAAs (Table 4), showed a better performance in the full spectral range (400-750 $\mathrm{nm}$ ) with an average NRMSE of $30.71 \%$ for the Funil Reservoir and $14.51 \%$ for the Itumbiara Reservoir. The highest error in estimation of $a(\lambda)$ in the Funil Reservoir was found between 500 and $600 \mathrm{~nm}$ with an average NRMSE of 130.61\%; and for the Itumbiara Reservoir, the highest error was found between 400 and $500 \mathrm{~nm}$ with an average NRMSE of $31.84 \%$. QAA ${ }_{C D O M}$ seems to work better in Itumbiara Reservoir, since for $a(\lambda)$ estimation the NRMSE were lower than $35 \%$ for all spectral ranges while for Funil Reservoir NRMSE values for the shorter spectral ranges were higher than $35 \%$ (Table 5 ). This difference is mainly related to the fact that $a_{C D M}(\lambda)$ for Funil Reservoir does not follow the typical exponential decrease feature due to the high concentration of CDOM, even in higher wavelengths. As discussed earlier this characteristic has influenced the others QAAs, however, utilizing the same dataset QAA $_{\text {CDOM }}$ was able to significantly reduce the NRMSE to $30.71 \%$ for the full spectral range ( $400-750 \mathrm{~nm}$ ) which is a major improvement over QAA $\mathrm{L}_{\mathrm{L} 9}$ (499.78\%), $\mathrm{QAA}_{\mathrm{M} 14}(389.96 \%)$, and $\mathrm{QAA} \mathrm{L}_{\mathrm{L} 15}$ (4077.71\%).

To better evaluate the estimation of $a(\lambda)$, we compared the measured and estimated values at three wavelengths in the blue range of MERIS/OLCI spectral bands: 412, 443 and $490 \mathrm{~nm}$. The blue range was selected because it showed to have major problems for the others existing QAAs. A scatter plot between the estimated and measured $a(412), a(443)$, and $a(490)$ was used to evaluate the performance for each study site (Fig. 8). For the Funil Reservoir (Fig. 8A), QAA $\mathrm{CDOM}_{\mathrm{C}}$ underestimated $a(\lambda)$ for the three wavelengths. The linear regression analysis for these three wavelengths showed a strong and significant correlation with a $\mathrm{R}^{2}$ of $0.76(\mathrm{p}<0.001)$. For the Itumbiara Reservoir, QAA ${ }_{\mathrm{CDOM}}$ showed no specific $a(\lambda)$ estimation trend at the three wavelengths (Fig. 8B). The linear regression analysis revealed a weak but significant correlation with a $\mathrm{R}^{2}$ of $0.11(\mathrm{p}=0.002)$. Table 5 suggests that in the blue spectral range, the $\mathrm{QAA}_{\mathrm{CDOM}}$ performs better in Itumbiara Reservoir (NRMSE of $31.84 \%$ ) than in Funil Reservoir (NRMSE of 51.01\%); however, this analysis showed that although the $\mathrm{R}^{2}$ is higher for Funil Reservoir, the scatterplot from Itumbiara Reservoir show to fit close to the $1: 1$ line (Fig. 8). The source of errors in the blue spectral range could be 

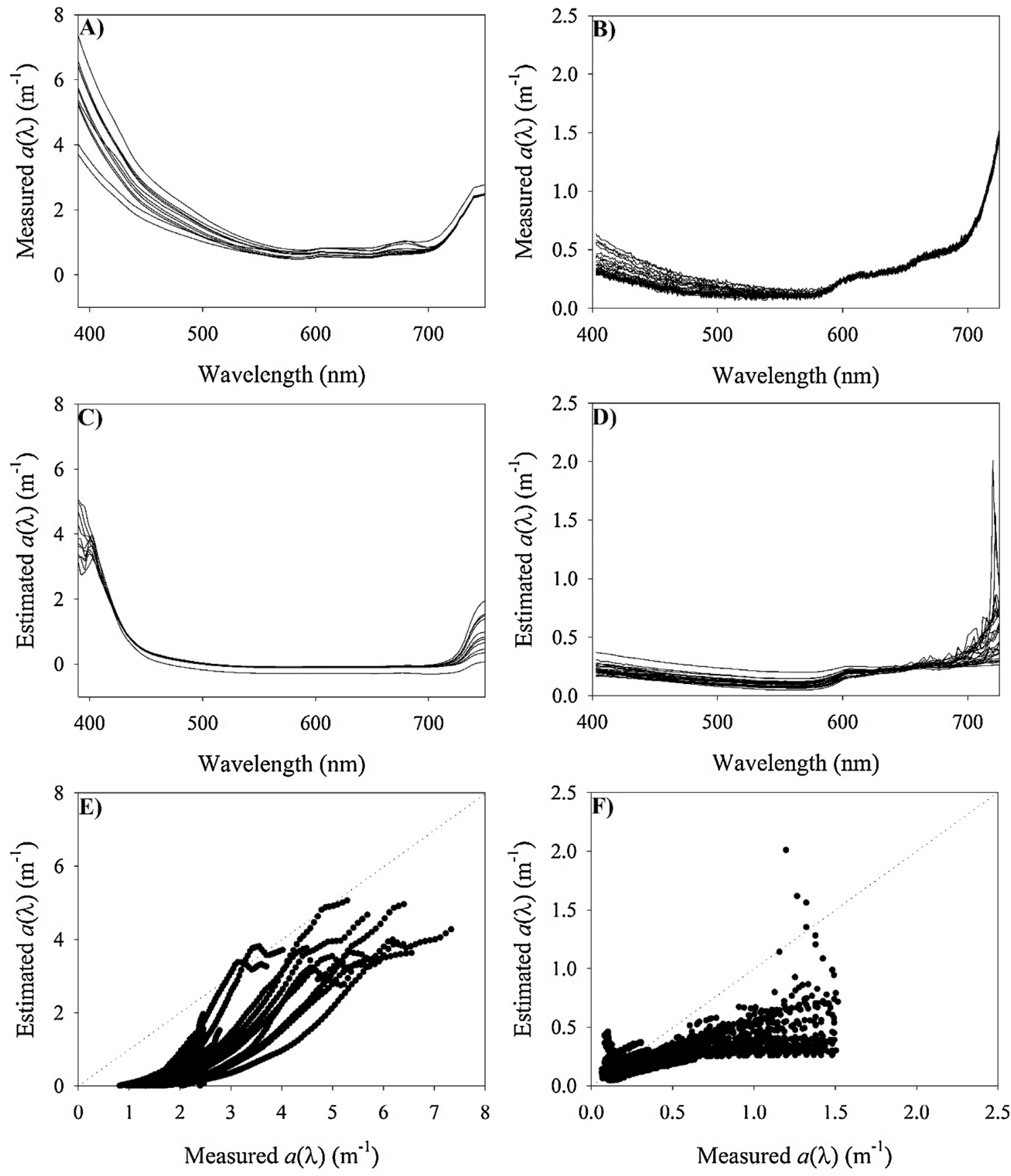

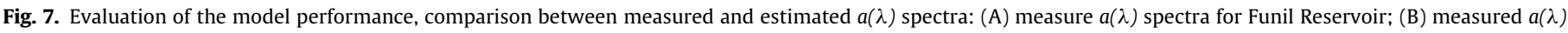

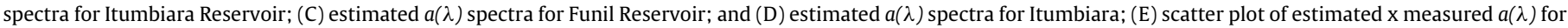
Funil Reservoir; and (F) scatter plot of estimated x measured $a(\lambda)$ for Itumbiara Reservoir.

explained by the high values of $a_{\mathrm{CDOM}}$ in Funil Reservoir, which also have a large variance in this range. Itumbiara Reservoir has lower errors since the absorption values in the blue spectral range do not vary as much as in Funil Reservoir. Overall, $\mathrm{QAA} \mathrm{CDOM}_{\mathrm{M}}$ was not only able to retrieve the spectral shape of $a(\lambda)$ but also the magnitude to an significant extent compared to the measured values and existing QAAs. However, when analyzed for specific wavelength range, the performance of the QAA stated before, a large source of error in the estimation of $a(\lambda)$ is the use of fixed values of $g_{1}$ and $g_{2}$ in order to make the algorithm easily operational. Further research should be done to evaluate if fine tuning of $g_{1}$ and $g_{2}$ would improve the estimation of $a(\lambda)$ in CDOM dominated waters. Nevertheless, the overall accuracy of
$30.71 \%$ for the full spectral range $(400-750 \mathrm{~nm}$ ) was sufficient for the decomposition and estimation of the others IOPs.

\subsubsection{Retrieval of $\mathrm{a}_{C D M}(\lambda)$}

Measured and estimated $a_{C D M}(\lambda)$ spectra for both study sites were also compared (Fig. 9). The measured $a_{C D M}(\lambda)$ for Funil (Fig. 9A) and Itumbiara (Fig. 9B) Reservoirs showed significant differences in magnitude. Funil Reservoir exhibited $a_{C D M}(\lambda)$ values 10 times higher than Itumbiara Reservoir, however, both showed similar spectral shape. The estimated $a_{C D M}(\lambda)$ spectra using QAA for Funil (Fig. 9C) and Itumbiara (Fig. 9D) Reservoirs, differ widely from the ones estimated by other QAAs (Fig. 5), but were able to produce similar spectral shape and magnitude as the measured 
Table 5

Average RMSE and NRMSE for the QAA ${ }_{C D O M}$ in Funil and Itumbiara Reservoirs.

\begin{tabular}{|c|c|c|c|c|c|c|}
\hline \multicolumn{7}{|c|}{ QAA $_{C D O M}$-Funil Reservoir } \\
\hline $\operatorname{RMSE}\left(\mathrm{m}^{-1}\right)$ & $a(400-750 \mathrm{~nm})$ & 1.28 & $a_{C D M}(400-750 \mathrm{~nm})$ & 0.63 & $a_{p h y}(400-750 \mathrm{~nm})$ & 0.08 \\
\hline NRMSE (\%) & & 30.71 & & 14.89 & & 25.90 \\
\hline $\operatorname{RMSE}\left(\mathrm{m}^{-1}\right)$ & $a(400-500 \mathrm{~nm})$ & 1.77 & $a_{C D M}(400-500 \mathrm{~nm})$ & 0.68 & $a_{p h y}(400-500 \mathrm{~nm})$ & 0.14 \\
\hline NRMSE (\%) & & 51.01 & & 23.12 & & 54.78 \\
\hline $\operatorname{RMSE}\left(\mathrm{m}^{-1}\right)$ & $a(500-600 \mathrm{~nm})$ & 0.95 & $a_{C D M}(500-600 \mathrm{~nm})$ & 0.68 & $a_{p h y}(500-600 \mathrm{~nm})$ & 0.04 \\
\hline NRMSE (\%) & & 130.61 & & 80.38 & & 79.42 \\
\hline $\operatorname{RMSE}\left(\mathrm{m}^{-1}\right)$ & $a(600-750 \mathrm{~nm})$ & 1.04 & $a_{C D M}(600-750 \mathrm{~nm})$ & 0.51 & $a_{p h y}(600-750 \mathrm{~nm})$ & 0.04 \\
\hline NRMSE (\%) & & 55.62 & & 139.63 & & 23.51 \\
\hline \multicolumn{7}{|c|}{$\mathrm{QAA}_{\mathrm{CDOM}}$-Itumbiara Reservoir } \\
\hline $\operatorname{RMSE}\left(\mathrm{m}^{-1}\right)$ & $a(400-750 \mathrm{~nm})$ & 0.20 & $a_{C D M}(400-750 \mathrm{~nm})$ & 0.04 & $a_{p h y}(400-750 \mathrm{~nm})$ & 0.01 \\
\hline NRMSE (\%) & & 14.51 & & 8.95 & & 29.76 \\
\hline $\operatorname{RMSE}\left(\mathrm{m}^{-1}\right)$ & $a(400-500 \mathrm{~nm})$ & 0.09 & $a_{C D M}(400-500 \mathrm{~nm})$ & 0.06 & $a_{\text {phy }}(400-500 \mathrm{~nm})$ & 0.01 \\
\hline NRMSE (\%) & & 31.84 & & 21.03 & & 91.84 \\
\hline $\operatorname{RMSE}\left(\mathrm{m}^{-1}\right)$ & $a(500-600 \mathrm{~nm})$ & 0.04 & $a_{C D M}(500-600 \mathrm{~nm})$ & 0.03 & $a_{p h y}(500-600 \mathrm{~nm})$ & 0.01 \\
\hline NRMSE (\%) & & 30.43 & & 22.48 & & 44.47 \\
\hline $\operatorname{RMSE}\left(\mathrm{m}^{-1}\right)$ & $a(600-750 \mathrm{~nm})$ & 0.30 & $a_{C D M}(600-750 \mathrm{~nm})$ & 0.02 & $a_{p h y}(600-750 \mathrm{~nm})$ & 0.01 \\
\hline NRMSE (\%) & & 24.28 & & 26.61 & & 31.92 \\
\hline
\end{tabular}
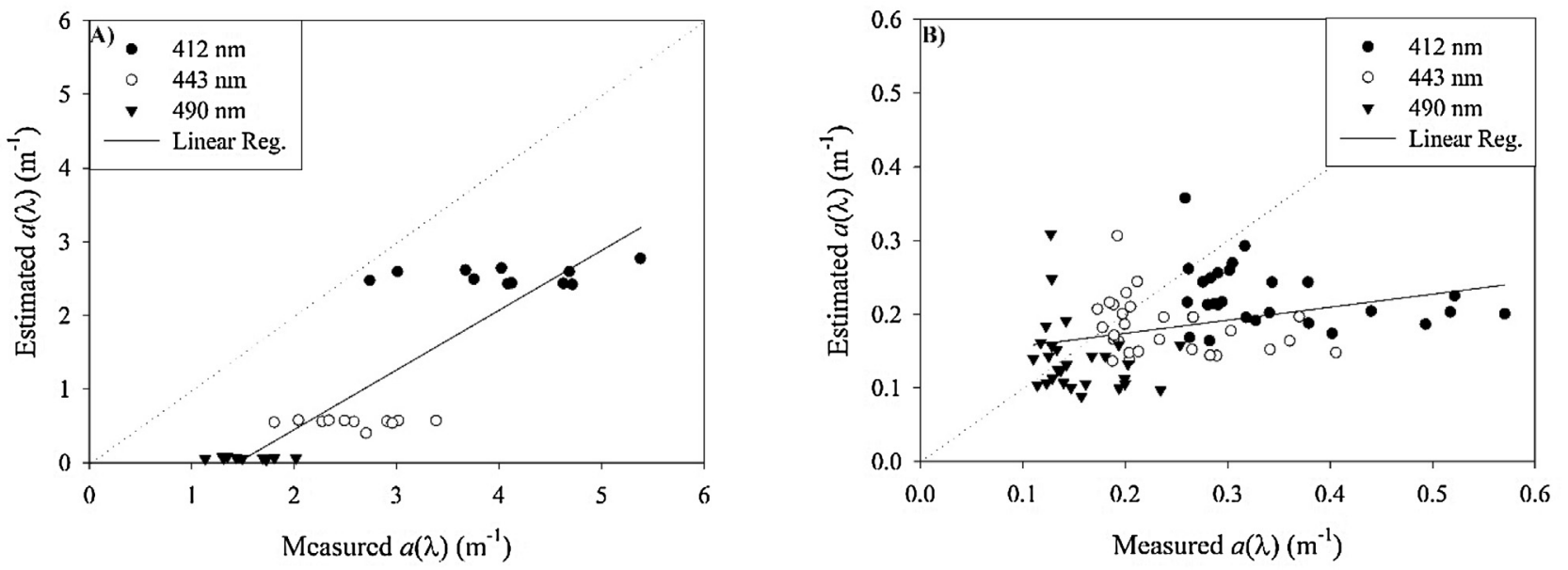

Fig. 8. Scatter plot for the estimated and measured $a(412), a(443)$ and $a(490)$ for (A) Funil Reservoir and (B) Itumbiara Reservoir.

$a_{C D M}(\lambda)$ with high absorption in the lower wavelengths and an exponential decrease in the higher wavelengths. Overall, the estimation of $a_{C D M}(\lambda)$ for the spectral range between $400-750 \mathrm{~nm}$ using QAA $A_{C D O M}$ showed a NRMSE of $14.89 \%$ and $8.95 \%$ for Funil and Itumbiara Reservoir respectively (Table 5). For both study sites the NRMSE values increased with wavelength. For the spectral ranges of $400-500 \mathrm{~nm}, 500-600 \mathrm{~nm}$, and $600-750 \mathrm{~nm}$ the NRMSE were 23.12\%, 80.38\% and $139.63 \%$ for the Funil Reservoir and $21.03 \%$, $22.48 \%$ and $26.61 \%$ for the Itumbiara Reservoir. This difference can be explained by the fact that $a_{C D M}(\lambda)$ in Funil Reservoir are dominant with $57 \%$ of the total IOP budge at $665 \mathrm{~nm}$ in which it should be low. For the Itumbiara Reservoir, the $a_{C D M}(\lambda)$ follows the expected pattern of being minimal with almost a $0 \%$ contribution to the total IOP budget at $665 \mathrm{~nm}$ (Fig. 3). The dominance of $a_{C D M}(\lambda)$ at higher wavelengths increased the NRMSE of $a_{C D M}(\lambda)$ estimation in green and red-NIR spectral ranges for Funil Reservoir.

Since the use of $a_{C D M}(\lambda)$ is usually based on its values in the blue range (Kutser et al., 2005), the performance of $Q A A_{C D O M}$ was analyzed in that wavelength range. QAA $\mathrm{CDOM}_{\mathrm{C}}$ produced an NRMSE of $23.12 \%$ and $21.03 \%$ in the blue spectral range for Funil and Itumbiara reservoirs, respectively. Fig. $9 \mathrm{E}$ and $\mathrm{F}$ show the scatter plots between estimated and measured $a_{C D M}(\lambda)$ for Funil and Itumbiara Reservoirs. For the Funil Reservoir, the estimated $a_{C D M}(\lambda)$ spectra showed consistent overestimation while in Itumbiara Reservoir the estimated $a_{C D M}(\lambda)$ showed a greater spread around the 1:1 line.
The performance of $\mathrm{QAA}_{\mathrm{CDOM}}$ in predicting $a_{C D M}(\lambda)$ for both reservoirs were analyzed at three fixed wavelengths in the blue spectral range: 412,443 , and $490 \mathrm{~nm}$. These wavelengths were chosen to match to the spectral bands from the MERIS and OLCI sensors (Fig. 10). For the Funil Reservoir (Fig. 10A), QAA $A_{\mathrm{CDOM}}$ was able to predict $a_{C D M}(\lambda)$ for the three wavelengths without showing a trend of over or underestimation $\left(R^{2}=0.77 ; p<0.001\right)$, whereas, a clear trend of underestimation was observed for the Itumbiara Reservoir $\left(\mathrm{R}^{2}=0.49 ; \mathrm{p}<0.001\right)$ (Fig. 10B). The NRMSE for the $a_{C D M}(\lambda)$ estimation in the blue spectral range showed $23.12 \%$ for Funil and $21.03 \%$ for Itumbiara Reservoir (Table 5). These values of NRMSE were consistent to the scatterplots which showed that the regression line was very close to the $1: 1$ line (Fig. 10). These results highlight the accuracy of $\mathrm{QAA}_{\mathrm{CDOM}}$ for the blue spectral range, which is usually the range used for the estimation of CDM.

\subsubsection{Retrieval of $\mathrm{a}_{\text {phy }}(\lambda)$}

Estimated and measured $a_{p h y}(\lambda)$ spectra for both datasets were compared to evaluate the performance of QAA ${ }_{C D O M}$ (Fig. 11). The measured spectra for Funil (Fig. 11A) and Itumbiara (Fig. 11B) showed a similar shape for both datasets, however, the magnitude of the $a_{p h y}(\lambda)$ was different. The estimated spectra for Funil (Fig. 11C) and Itumbiara (Fig. 11D) Reservoirs showed that the $\mathrm{QAA}_{\mathrm{CDOM}}$ was able to retrieve the shape of $a_{\text {phy }}(\lambda)$ which was not possible using the existing QAAs (Fig. 6). This was possible 

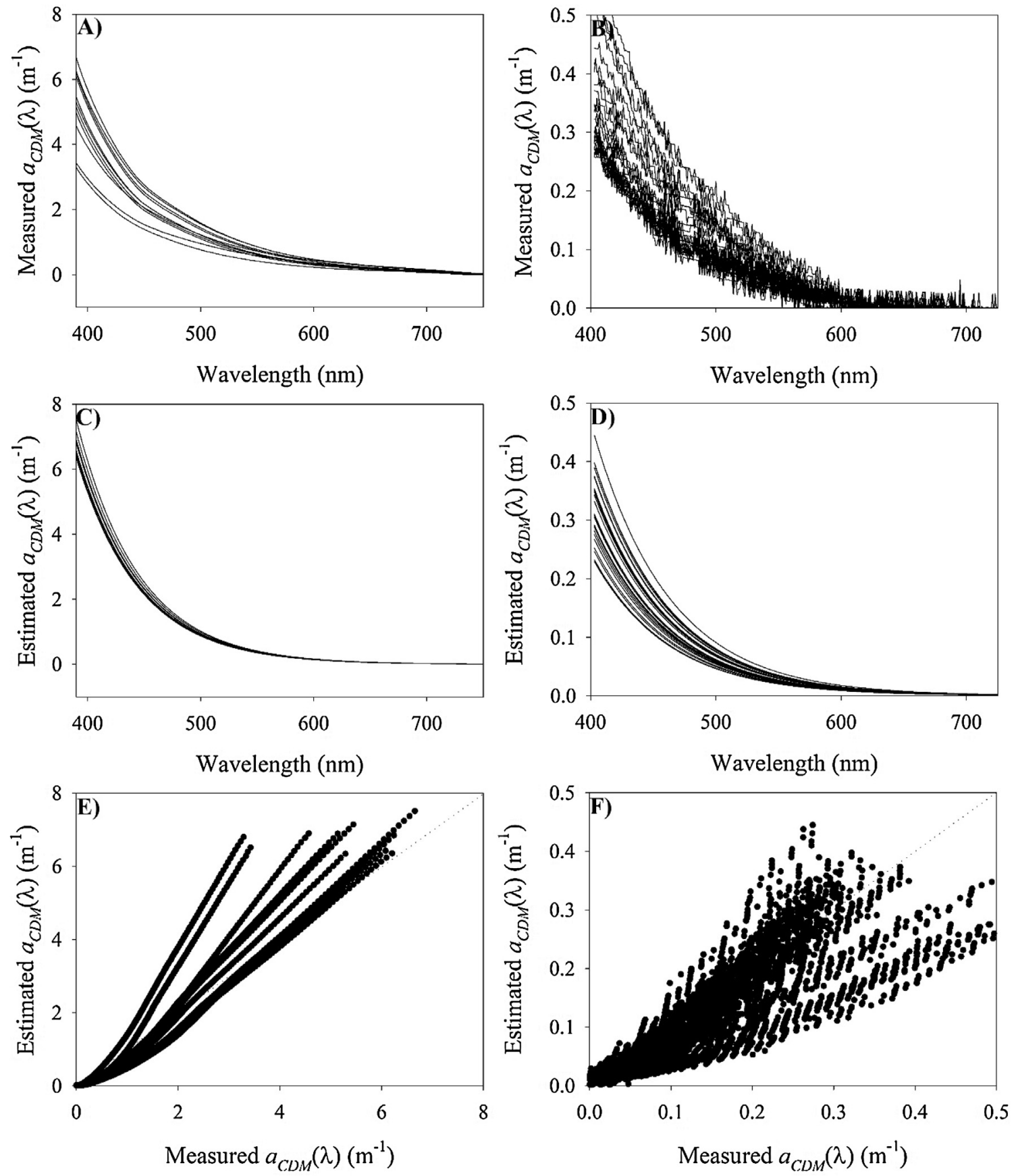

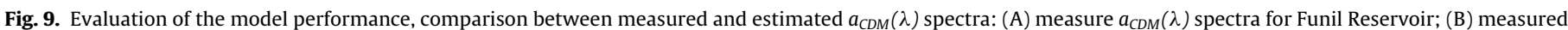

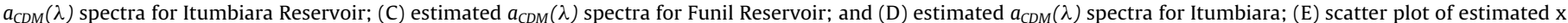
measured $a_{C D M}(\lambda)$ for Funil Reservoir; and (F) scatter plot of estimated x measured $a_{C D M}(\lambda)$ for Itumbiara Reservoir.

due to the unique use of $a^{+}{ }_{p h y}(\lambda)$ in the computation of $a_{p h y}(\lambda)$ in $\mathrm{QAA}_{\mathrm{CDOM}}$. The absorption peak at approximately $665 \mathrm{~nm}$ was observed in both estimated $a_{\text {phy }}(\lambda)$ spectra, however, when compared to the measured spectra, the blue range showed different magnitudes and shape. This difference was also noticed in the NRMSE values for different spectral ranges (Table 5). For the full spectral range ( $400-750 \mathrm{~nm}$ ), the NRMSE were $25.90 \%$ and $29.76 \%$ for Funil and Itumbiara Reservoirs respectively; and the lower spectral range $(400-500 \mathrm{~nm}$ ) showed NRMSE of $54.78 \%$ for Funil Reservoir and 91.84 for Itumbiara Reservoir. For the ranges from 500 to $600 \mathrm{~nm}$ and $600-750 \mathrm{~nm}$, the NRMSE values were $79.42 \%$ and $23.51 \%$ for Funil Reservoir and $44.47 \%$ and $31.92 \%$ for Itumbiara
Reservoir. Since the chl- $a$ absorption peak is around $665 \mathrm{~nm}$, the values of NRMSE for the range between 600 and $750 \mathrm{~nm}$ showed to be appropriate if compared to others QAAs (Table 4). Fig. 11E and $\mathrm{F}$ shows the relationship between estimated and measured $a_{\text {phy }}(\lambda)$ for both reservoirs. Estimated $a_{\text {phy }}(\lambda)$ spectra for both study sites showed an overall trend of underestimation, probably because of the high absorption of CDOM at $412 \mathrm{~nm}$ which influences the estimation of $a_{\text {phy }}\left(\lambda_{0}\right)$ (Eq. (28)).

$\mathrm{QAA}_{\mathrm{CDOM}}$ outperformed others QAAs in retrieving not only the shape but also the magnitude of $a_{p h y}(\lambda)$. We evaluated the accuracy of $a_{\text {phy }}(\lambda)$ estimation at three fixed wavelengths based on the spectral bands of MERIS and OLCI sensors; 560, 620, and $665 \mathrm{~nm}$. Scatter 

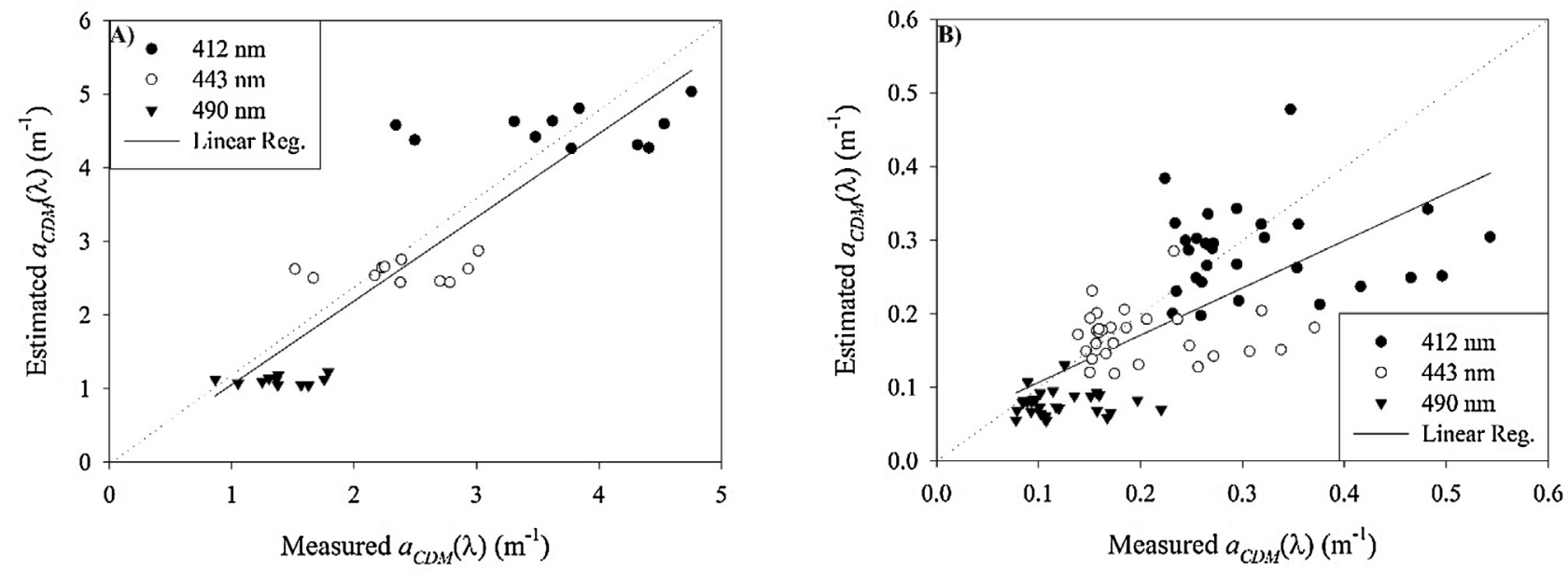

Fig. 10. Scatter plot for the estimated and measured $a_{C D M}(412), a_{C D M}(443)$ and $a_{C D M}(490)$ for (A) Funil Reservoir and (B) Itumbiara Reservoir.

plots between the estimated and measured $a_{\text {phy }}(560), a_{\text {phy }}(620)$, and $a_{p h y}(665)$ from both study sites are shown in Fig. 12. Both linear trend lines showed a pattern of underestimation for the three wavelengths. Linear regression showed a $R^{2}$ of $0.38(p=0.001)$ for Funil Reservoir and a $R^{2}$ of $0.25(p<0.001)$ for Itumbiara Reservoir. Overall results demonstrate that $\mathrm{QAA}_{\mathrm{CDOM}}$ (Fig. 12) has the potential to estimate $a_{\text {phy }}(\lambda)$ accurately compared to other QAAs (Fig. 6) in CDOM dominated waters when using the full spectral range. However, for specific wavelength ranges, the performance of the $\mathrm{QAA}_{\mathrm{CDOM}}$ may not seem satisfactory (Table 5). The variation in errors among spectral regions can be related to the residual interference of CDOM, since errors for $a_{\text {phy }}(\lambda)$ were lower at higher wavelengths. Moreover, the use of a $a^{+}$phy $(\lambda)$ computed for marine phytoplankton can also be a source of error in the estimation of $a_{p h y}(\lambda)$. Future research should be focused on further evaluating the differences between $a^{+}$phy $(\lambda)$ computed from marine and freshwater phytoplankton to improve the estimation of $a_{p h y}(\lambda)$.

It is important to highlight that $\mathrm{QAA}_{\mathrm{CDOM}}$ performance was evaluated for two different aquatic systems with distinct optical properties. Although both reservoirs can be considered as CDOM dominated waters, the differences on the OAC composition was easily noticeable. In accordance with that conclusion, $\mathrm{QAA} \mathrm{ADOM}_{\mathrm{CDO}}$ showed to perform the best when CDOM dominance was not extreme such as for Itumbiara Reservoir. However, even in sites where CDOM dominance is extreme, such as Funil Reservoir, it was possible to retrieve $a(\lambda), a_{C D M}(\lambda)$ and $a_{p h y}(\lambda)$ with NRMSE less than $31 \%$ for the full spectral range $(400-750 \mathrm{~nm})$. Possible sources of errors in $\mathrm{QAA}_{\mathrm{CDOM}}$ could be related to the $r_{r s}$ computation, since different instruments were used to measure in situ $E_{d}$ and $L_{u}$. In addition, human errors in the quantification of the reference measurements should also be considered.

In summary, $a(\lambda)$ estimation for the $400-750 \mathrm{~nm}$ range had a NRMSE of $30.71 \%$ and $14.51 \%$ for Funil and Itumbiara Reservoir, respectively; $a_{C D M}(\lambda)$ estimations for the same spectral range produced NRMSE of $14.89 \%$ and $8.95 \%$ for Funil and Itumbiara Reservoir. $a_{p h y}(\lambda)$ estimation, compared to other QAAs, showed a much improved performance with a NRMSE of $25.90 \%$ and $29.76 \%$ for Funil and Itumbiara Reservoirs in the spectral range from 400 to $750 \mathrm{~nm}$ mainly due to the use of ${a^{+}}_{p h y}(\lambda)$ from Lee et al. (2010).

\section{Conclusions}

In this research, three existing variants of QAA (Lee et al., 2009; Mishra et al., 2014; Li et al., 2015) were applied to two CDOM dominated tropical reservoirs to estimate IOPs. However, none of the
QAAs were able to successfully retrieve the IOPs. $a_{\text {phy }}(\lambda)$ retrieval errors were the highest for the three tested QAAs when compared to the measured spectra. The poor performance highlighted the need for a re-parameterization of the QAAs for CDOM rich tropical waters such as Funil and Itumbiara Reservoirs. QAA developed by parameterizing the QAA proposed by Mishra et al. (2014) to predict IOPs from CDOM dominated inland water bodies using proximal remote sensing data. The wavelengths used in $\mathrm{QAA}_{\mathrm{CDOM}}$ were chosen to match the spectral bands of MERIS and OLCI sensors. The primary difference among previous QAAs and QAA $A_{C D O M}$ was associated with the retrieval of $a_{p h y}(\lambda)$ based on the algorithm proposed by Lee et al. (2010) and the use of the normalized phytoplankton absorption coefficient from Roesler et al. (1989). It is the first time, to the best of our knowledge, that such an modification was used in a QAA, and it was proposed to improve the prediction of $a_{p h y}(\lambda)$ which simply failed when implementing existing QAAs. Existing QAAs performed poorly because the study sites used to develop those QAAs were eutrophic to hypereutrophic waters. Therefore, the re-parametrization of an existing QAA for CDOM dominated waters needed a novel approach to estimate $a_{p h y}(\lambda)$ which would enhance the phytoplankton signal and that was possible due to the use of the normalized phytoplankton absorption coefficient. Other improvements included the addition of two factors, $C_{1}$ and $C_{2}$ to correct for the high absorption by CDOM. These factors which were used to minimize the CDOM interference were tuned based on the ratio between the $r_{r s}(443)$ and $r_{r s}(560)$ for $\mathrm{C}_{1}$ and the absolute ratio between the $a(665)$ and $a(412)$ multiplied by 10 for $C_{2}$. It is also important to highlight that QAA able to outcompete other QAAs applied in tropical reservoirs even in datasets that used different methodologies for the computation of in situ IOPs and $R_{r s}$. This fact showed that $\mathrm{QAA}_{\mathrm{CDOM}}$ is applicable even when there is a variation in equipment used and methodologies employed for analytical extraction of IOPs. Nevertheless, this can also be a source of uncertainty for the algorithm mainly using different instruments for measuring the $R_{r s}$. Therefore, considering these facts the achieved results in the estimation of IOPs seems satisfactory with average NRMSEs of average $30.71 \%$ and $14.51 \%$ for $a(400-750), 14.89 \%$ and $8.95 \%$ for $a_{C D M}(400-750)$ and $25.90 \%$ and $29.76 \%$ for $a_{p h y}(400-750)$ in Funil and Itumbiara Reservoirs, Brazil respectively.

Overall performance of the new $\mathrm{QAA}_{\mathrm{CDOM}}$ was better than the existing QAAs, however, it is clear that further tuning and validation of $\mathrm{QAA}_{\mathrm{CDOM}}$ is necessary, particularly for $a(\lambda)$ and $a_{\text {phy }}(\lambda)$ estimation, by incorporating optical data from water bodies over broad geographic areas to increase its IOP prediction accu- 

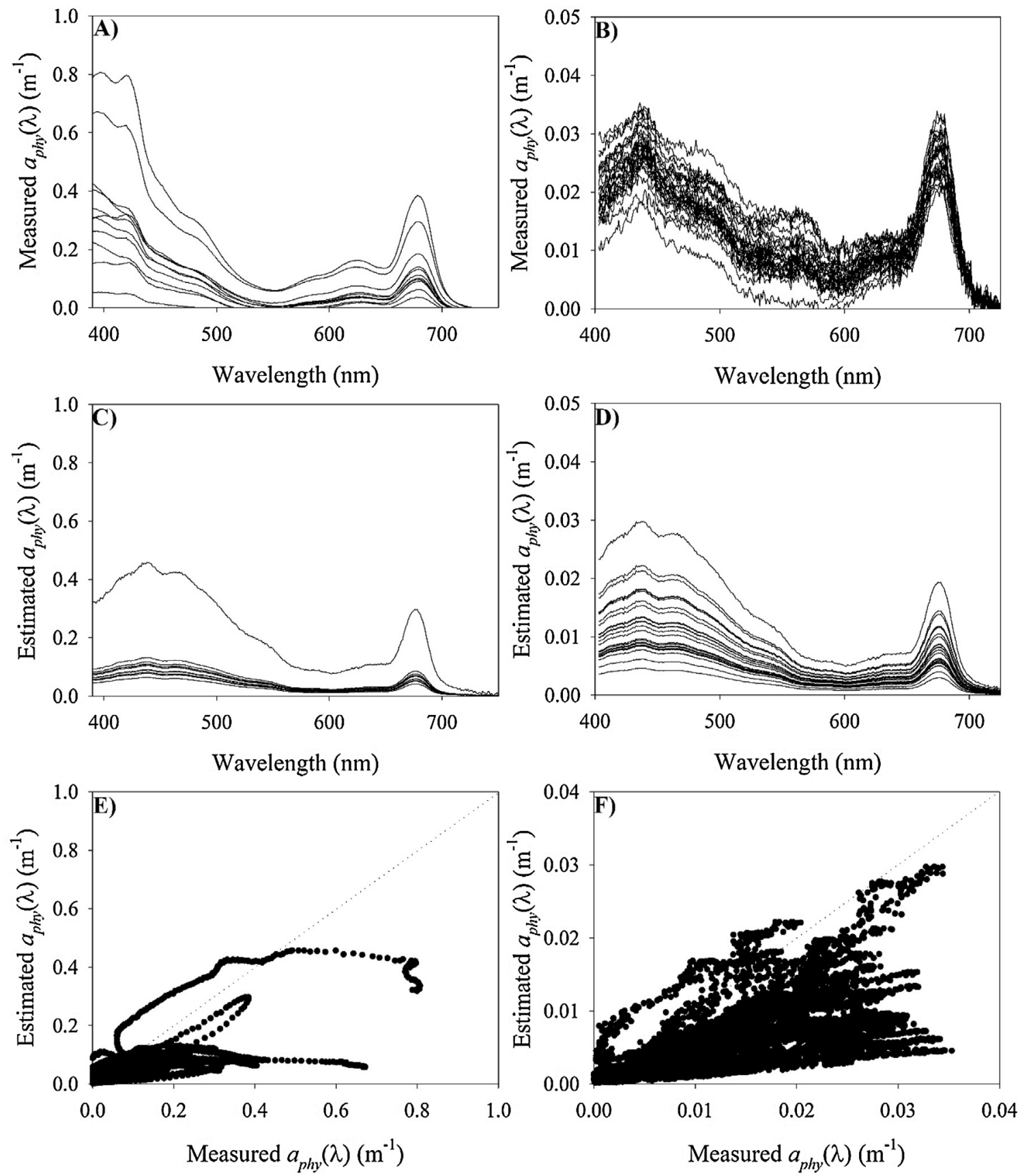

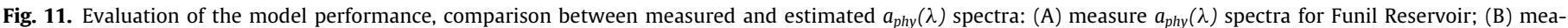

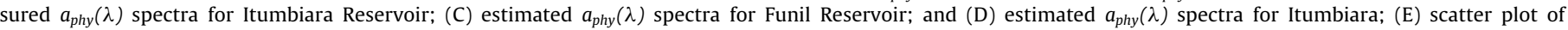
estimated $\times$ measured $a_{p h y}(\lambda)$ for Funil Reservoir; and (F) scatter plot of estimated $\times$ measured $a_{\text {phy }}(\lambda)$ for Itumbiara Reservoir.

racy. The major modifications from the original QAA in its 5th version (Lee et al., 2009) are: '(i) the use of $g_{0}$ and $g_{1}$ values proposed by Mishra et al. (2014); (ii) the use of different wavelengths for the calculation of $\chi$ (Eq. (17)) in order to fit MERIS and OLCI spectral bands as well as the water type (CDOM dominant); (iii) the use of a factor to compute the influence of CDOM based on a blue-green ratio $\left(C_{1}\right)$ to calculate $a(\lambda)$ (Eq. (21).); (iv) the inclusion of a semi-analytical methods to compute the $a_{p h y}(\lambda)$ (Eqs. (27) and (28)). The tuning of $C_{1}$ and $C_{2}$ using data from widely varying geographic areas should enhance the performance of $\mathrm{QAA}_{\mathrm{CDOM}}$ in high CDOM waters. The results from Funil and Itumbiara Reservoirs highlight the importance of these factors since it improved the estimation of the IOPs. While the QAA $\mathrm{CDOM}_{\mathrm{M}}$ worked well for tropi- cal CDOM dominated waters, the validation of the algorithm with additional data from other water bodies is necessary to enhance its accuracy and make it operational for CDOM dominated waters. Therefore, a global database of inland water optical properties is needed to improve the accuracy of our proposed algorithm since it will increase the variability in the CDOM concentration. Also, a better tuning of the factors $C_{1}$ and $C_{2}$ can be achieved by calibrating them based on the percentage of in CDOM dominance. QAA $A_{C D O M}$ was developed using a hyperspectral sensor, however, all the spectral bands used in the algorithm were chosen to match the spectral bands of MERIS and OLCI sensors. Thus, a field campaign with a concomitant satellite image acquisition is necessary to evaluate the applicability of $\mathrm{QAA}_{\mathrm{CDOM}}$ to orbital sensors. 

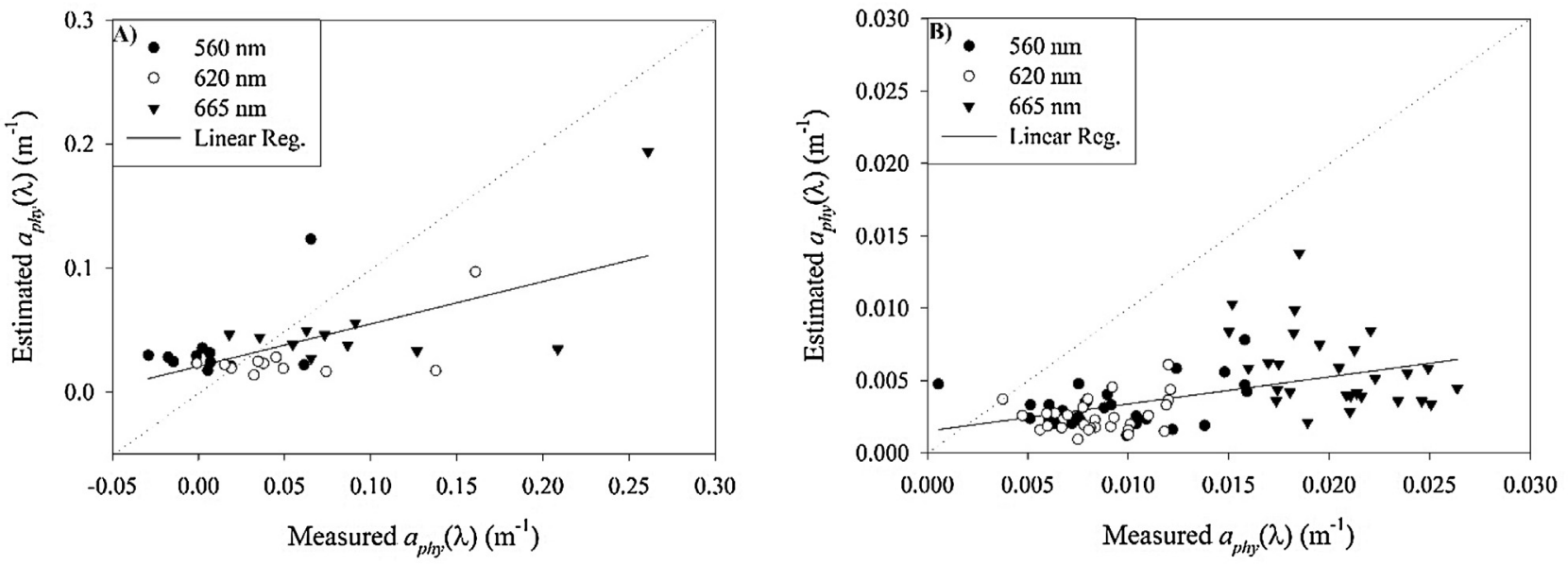

Fig. 12. Scatter plot for the estimated and measured $a_{p h y}(560), a_{p h y}(620)$ and $a_{p h y}(665)$ for (A) Funil Reservoir and (B) Itumbiara Reservoir.

Future research studies should attempt to apply $\mathrm{QAA}$ CDOM to MERIS or OLCI imagery in order to evaluate the potential of the algorithm as a regular product for satellite data. To further evaluate the algorithm in a global scale, databases such as the Lake Bio-optical Measurements and Matchup Data for Remote Sensing (LIMNADES) are essential to enhance the variability within the tested dataset. Moreover, future research can also evaluate the proposed structure of $\mathrm{QAA} \mathrm{C}_{\mathrm{CDOM}}$ to apply it to different waters types (dominated by other constituents) by only changing the factors $C_{1}$ and $C_{2}$. It could lead to a more operational use of QAA since only the water type would be necessary for its application to different aquatic systems.

\section{Acknowledgements}

Authors thank São Paulo Research Foundation (FAPESP), Brazil grants 2007/08103-2 and 2011/19523-8, for providing funding for this work. We also thank the Coordination for the Improvement of Higher Education Personnel (CAPES), Brazil for the scholarship grant. Special thanks to the Office of International Education at the University of Georgia (UGA), USA for facilitating the collaboration between the INPE and UGA through the international student internship program. Authors also thank Dr. Aurea Ciotti and Dr. Salvador A. Gaetta for the IOPs analysis. I.O. thanks Marcelo P. Curtarelli, Joaquim A. D. Leão, Carlos A. Araujo, Rafael D. Ferreira, Carina R. Macedo and Renato M.P. Ferreira for the support in the field work.

\section{References}

Alcântara, E.H., Bonnet, M.P., Assireu, A.T., Stech, J.L., Novo, E.M.L.M., Lorenzzetti, J.A., 2010. On the water thermal response to the passage of cold fronts: initial results for Itumbiara reservoir (Brazil). Hydrol. Earth Syst. Sci. Discuss. 7, 9437-9465.

Aurin, D.A., Dierssen, H.M., 2012. Advantages and limitations of ocean color remote sensing in CDOM-dominated: mineral-rich coastal and estuarine waters. Remote Sens. Environ. 125, 181-197.

Babin, M., Stramski, D., Ferrari, G.M., Claustre, H., Bricaud, A., Obolensky, G., Hoepffner, N., 2003. Variations in the light absorption coefficients of phytoplankton, nonalgal particles, and dissolved organic matter in coastal waters around Europe. J. Geophys. Res. 108 (C7), 3211.

Branco, C.W.C., Rocha, M.I.A., Pinto, G.F.S., Gômara, G.A., Filippo, R., 2002. Limnological features of Funil Reservoir (R.J.: Brazil) and indicator properties of rotifers and cladocerans of the zooplankton community. Lakes Reservoirs: Res. Manage. 7, 87-92.

Ciotti, A.M., Cullen, J.J., Lewis, M.R., 1999. A semi-analytical model of the influence of phytoplankton community structure on the relationship between light attenuation and ocean color. J. Geophys. Res. 104 (C1), 1559-1578.

Curtarelli, M., Alcântara, E., Rennó, C., Stech, J., 2013a. Effects of cold fronts on MODIS-derived sensible and latent heat fluxes in Itumbiara reservoir (Central Brazil). Adv. Space Res. 52, 1668-1677.
Curtarelli, M.P., Alcântara, E.H., Rennó, C.D., Assireu, A.T., Bonnet, M.P., Stech, J. 2013b. Modelling the surface circulation and thermal structure of a tropical reservoir using three-dimensional hydrodynamic lake model and remote-sensing data. Water Environ. J., http://dx.doi.org/10.1111/wej.12066.

Dall'Olmo, G., Gitelson, A.A., 2005. Effect of bio-optical parameter variability on the remote estimation of chlorophyll-a concentration in turbid productive waters: experimental results. Appl. Opt. 44, 412-422.

Dittmar, T., Rezende, C.E., Manecki, M., Niggemann, J., Ovalle, A.R.C., Stubbins, A., Bernardes, M.C., 2012. Continuous flux of dissolved black carbon from a vanished tropical forest biome. Nat. Geosci. 5, 618-622.

Duan, H., Ma, R., Xu, J., Zhang, Y., Zhang, B., 2010. Comparison of different semi-empirical algorithms to estimate chlorophyll-a concentration in inland lake water. Environ. Monit. Assess. 170, 231-244.

Fougnie, B., Frouin, R., Lecomte, P., Deschamps, P.Y., 1999. Reduction of skylight reflection effects in the above-water measurement of diffuse marine reflectance. Appl. Opt. 38, 3844-3856.

Gilerson, A.A., Gitelson, A.A., Gurlin, D., Moses, W., Ioannou, I., Ahmed, S., 2010. Algorithms for remote estimation of chlorophyll-a in coastal and inland waters using red and near infrared bands. Opt. Express 18, 24109-24125.

Gitelson, A.A., Schalles, J.F., Hladik, C.M., 2007. Remote chlorophyll-a retrieval in turbid: productive estuaries: chesapeake bay case study. Remote Sens. Environ. 109, 464-472.

Gitelson, A.A., Dall'Olmo, G., Moses, W., Rundquist, D.C., Barrow, T., Fisher, T.R., Gurlin, D., Holz, J., 2008. A simple semi-analytical model for remote estimation of chlorophyll-a in turbid waters: validation. Remote Sens. Environ. 112, 3582-3593.

Gitelson, A.A., Gurlin, D., Moses, W.J., Barrow, T., 2009. A bio-optical algorithm for the remote estimation of the chlorophyll-a concentration in case 2 waters. Environ. Res. Lett. 4, 045003.

Gitelson, A.A., 1992. The peak near $700 \mathrm{~nm}$ on radiance spectra of algae and water: relationships of its magnitude and position with chlorophyll concentration. Int. J. Remote Sens. 13 (17), 3367-3373.

Gons, H.J., Rijkeboer, M., Ruddick, K.G., 2002. A chlorophyll-retrieval algorithm for satellite imagery (Medium Resolution Imaging Spectrometer) of inland and coastal waters. J. Plankton Res. 24, 947-951.

Gons, H.J., Auer, M.T., Effler, S.W., 2008. MERIS satellite chlorophyll mapping of oligotrophic and eutrophic waters in the Laurentian Great Lakes. Remote Sens. Environ. 112, 4098-4106.

Gons, H.J., 1999. Optical teledetection of chlorophyll-a in turbid inland waters. Environ. Sci. Technol. 33, 1127-1132.

Gordon, H.R., Broen, O.B., Jacobs, M.M., 1975. Computed relationships between the inherent and apparent optical properties of a flat homogeneous ocean. Appl. Opt. 14 (2), 417-427.

Gordon, H.R., Brown, O.B., Evans, R.H., Brown, J.W., Smith, R.C., Baker, K.S., Clark, D.K., 1988. A semianalytic radiance model of ocean color. J. Geophys. Res. 93 (D9), 10909-10924.

Hadjimitsis, D.G., Clayton, C., 2009. Assessment of temporal variations of water quality in inland water bodies using atmospheric corrected satellite remotely sensed image data. Environ. Monit. Assess. 159, 281-292.

Hu, C.M., Muller-Karger, F.E., Taylor, C., Carder, K.L., Kelble, C., Johns, E., et al., 2005. Red tide detection and tracing using MODIS fluorescence data: a regional example in SW Florida coastal waters. Remote Sens. Environ. 97, 311-321.

IOCCG, 2006. Remote Sensing of Inherent Optical Properties: Fundamentals, Tests of Algorithms, and Application. IOCCG, Dartmouth, Canada.

Kutser, T., Pierson, D.C., Tranvik, L., Reinart, A., Sobek, S., Kallio, K., 2005. Using satellite remote sensing to estimate the colored dissolved organic matter absorption coefficient in lakes. Ecosystems 8, 709-720.

Le, C.F., Li, Y.M., Zha, Y., Sun, D.Y., Yin, B., 2009a. Validation of a quasi-analytica algorithm for highly turbid eutrophic water of Meiliang Bay in Taihu Lake, China. IEEE Trans. Geosci. Remote Sens. 47, 2492-2500. 
Le, C.F., Li, Y.M., Zha, Y., Sun, D.Y., Huang, C.C., Lu, H., 2009b. A four-band semi-analytical model for estimating chlorophyll a in highly turbid lakes: the case of Taihu Lake, China. Remote Sens. Environ. 113, 1175-1182.

Le, C.F., Li, Y.M., Zha, Y., Sun, D.Y., Huang, C.C., Zhang, H., 2011. Remote estimation of chlorophyll a in optically complex waters based on optical classification. Remote Sens. Environ. 115, 725-737.

Lee, Z.P., Carder, K.L., 2004. Absorption spectrum of phytoplankton pigments derived from hyperspectral remote-sensing reflectance. Remote Sens. Environ. 89, 361-368

Lee, Z.P., Carder, K.L., Arnone, R.A., 2002. Deriving inherent optical properties from water color. A multiband quasi-analytical algorithm for optically deep waters. Appl. Opt. 41, 5755-5772.

Lee, Z.P., Lubac, B., Werdell, J., Arnone, R., 2009. An Update of the Quasi-Analytical Algorithm (QAA_v5) (available at: http://www.ioccg.org/groups/Software OCA/QAA_v5.pdf).

Lee, Z.P., Arnone, R., Hu, C., Werdell, J., Lubac, B., 2010. Uncertainties of optical parameters and their propagations in an analytical ocean color inversion algorithm. Appl. Opt. 49, 369-381.

Li, L., Li, L., Song, K., Li, Y., Shi, K., Li, Z., 2011. An improved analytical algorithm for remote estimation of chlorophyll-a in highly turbid waters. Environ. Res. Lett. 6 (034037), 1-7.

Li, L., Li, L., Shi, K., Li, Z., Song, K., 2012. A semi-analytical algorithm for remote estimation of phycocyanin in inland waters. Sci. Total Environ. 435-436, $141-150$.

Li, L., Li, L., Song, K., Li, Y., Tedesco, L.P., Shi, K., Li, Z., 2013. An inversion model for deriving inherent optical properties of inland waters: establishment: validation and application. Remote Sens. Environ. 135, 150-166.

Li, L., Li, L., Song, K., 2015. Remote sensing of freshwater cyanobacteria: an extended IOP Inversion Model of Inland Waters (IIMIW) for partitioning absorption coefficient and estimating phycocyanin. Remote Sens. Environ. 157, 9-23.

Lorenzen, C.J., 1967. Determination of chlorophyll and pheo-pigments: spectrophotometric equations. Limnol. Oceanogr. 12, 343-346.

Maritorena, S., Siegel, D.A., Peterson, A.R., 2002. Optimization of a semianalytical ocean color model for global-scale applications. Appl. Opt. 41, 2705-2714.

Matthews, M.W., Bernard, S., Winter, K., 2010. Remote sensing of cyanobacteriadominant algal blooms and water quality parameters in Zeekoevlei, a small hypertrophic lake, using MERIS. Remote Sens. Environ. 114, 2070-2087.

Mishra, S., Mishra, D.R., 2012. Normalized difference chlorophyll index: a novel model for remote estimation of chlorophyll-a concentration in turbid productive waters. Remote Sens. Environ. 117, 394-406.

Mishra, S., Mishra, D.R., 2014. A novel remote sensing algorithm to quantify phycocyanin in cyanobacterial algal blooms. Environ. Res. Lett. 9, 114003.

Mishra, S., Mishra, D.R., Schluchter, W.M., 2009. A novel algorithm for predicting phycocyanin concentrations in cyanobacteria: a proximal hyperspectral remote sensing approach. Remote Sens. 1, 758-775.

Mishra, S., Mishra, D.R., Lee, Z., 2013. Quantifying cyanobacterial phycocyanin concentration in turbid productive waters: a quasi-analytical approach. Remote Sens. Environ. 133, 141-151.

Mishra, S., Mishra, D.R., Lee, Z., 2014. Bio-optical inversion in highly turbid and cyanobacteria dominated waters. IEEE Trans. Geosci. Remote Sens. 52, 375-388.

Mobley, C.D., 1999. Estimation of the remote-sensing reflectance from above-surface measurements. Appl. Opt. 38, 7442-7455

Morel, A., 1974. Optical properties of pure water and pure sea water. In: Jerlov, N.G., Nielsen, E.S. (Eds.), Optical Aspects of Oceanography. Academic, San Diego, CA, USA, pp. 1-24.
Moses, W.J., Gitelson, A.A., Berdnikov, S., Povazhnyy, V., 2009. Estimation of chlorophyll-a concentration in case II waters using MODIS and MERIS data-successes and challenges. Environ. Res. Lett. 4 (045005), 1-8.

Mueller, J.L., Fargion, G.S., Mcclain, C.R., 2002. Oceans optics protocols for satellite ocean color sensor validation. Revision 4. Inherent Optical Properties, vol. IV. NASA, Greenbelt, pp. 76.

Mueller, J.L., 2000. In-water radiometric profile measurements and data analysis protocols. In: Fargion, G.S., Mueller, J.L. (Eds.), Ocean Optics Protocols for Satellite Ocean Color Sensor Validation. Goddard Space Flight Center Greenbelt, Maryland, pp. 87-97.

Nascimento, R.F.F., 2010. Utilização de dados MERIS e in situ para a caracterização bio-óptica do reservatório de Itumbiara, GO. Master Thesis. Instituto Nacional de Pesquisas Espaciais, São José dos Campos, Brazil (in Portuguese).

Nush, E.A., 1980. Comparison of different methods for chlorophyll and phaeopigment determination. Arch. Hydrobiol.: Beih. Ergebn. Limnol. 14 $14-36$.

Odermatt, D., Gitelson, A., Brando, V.E., Schaepman, M., 2012. Review of constituent retrieval in optically deep and complex waters from satellite imagery. Remote Sens. Environ. 118, 116-126.

Ogashawara, I., Mishra, D.R., Mishra, S., Curtarelli, M.P., Stech, J.L., 2013. A performance review of reflectance based algorithms for predicting phycocyanin concentrations in inland waters. Remote Sens. 5, 4774-4798.

Pope, R., Fry, E., 1997. Absorption spectrum (380-700 nm) of pure waters: II. Integrating cavity measurements. Appl. Opt. 36, 8710-8723.

Primo, A.R.R., 2006. Avaliação da influência do reservatório de Funil na qualidade da água do rio Paraíba do Sul. Master Thesis. São Paulo University, São Paulo, Brazil (in Portuguese).

Reinart, A., Kutser, T., 2006. Comparison of different satellite sensors in detecting cyanobacterial bloom events in the Baltic Sea. Remote Sens. Environ. 102, 74-85.

Rocha, M.I.A., Branco, C.W.C., Sampaio, G.F., Gômara, G.A., Filippo, R., 2002. Spatial and temporal variation of limnological features, Microcystis aeruginosa and zooplankton in a eutrophic reservoir (Funil Reservoir, Rio de Janeiro). Acta Limnol. Bras. 14, 73-86

Roesler, C.S., Perry, M.J., 1995. In situ phytoplankton absorption, fluorescence emission: and particulate backscattering spectra determined from reflectance. J. Geophys. Res. 100, 13279-13294.

Roesler, C.S., Perry, M.J., Carder, K.L., 1989. Modeling in situ phytoplankton absorption from total absorption spectra in productive inland marine waters. Limnol. Oceanogr. 34, 1510-1523.

Schalles, J.F., Yacobi, Y.Z., 2000. Remote detection and seasonal patterns of phycocyanin, carotenoid, and chlorophyll pigments in eutrophic waters. Arch. Hydrobiol. 55, 153-168.

Simis, S.G.H., Peters, S.W.M., Gons, H.J., 2005. Remote sensing of the cyanobacterial pigment phycocyanin in turbid inland water. Limnol. Oceanogr. 50, 237-245.

Simis, S.G.H., Ruiz-Verdu, A., Dominguez-Gomez, J.A., Pena-Martinez, R., Peters, S.W.M., Gons, H.J., 2007. Influence of phytoplankton pigment composition on remote sensing of cyanobacterial biomass. Remote Sens. Environ. 106, 414-427.

Smith, R.C., Baker, K.S., 1981. Optical properties of the clearest natural waters. Appl. Opt. 20, 177-184.

Tassan, S., Ferrari, G., 1995. An alternative approach to absorption measurements of aquatic particles retained on filters. Limnol. Oceanogr. 40, 1358-1368.

Wetzel, R.G., Likens, G.E., 1991. Limnological Analyses, 2 ed. Springer, New York, USA. 